Journal of Advanced Research in Fluid Mechanics and Thermal Sciences

\title{
An Exploratory Approach to Study Electro-Osmotic of Non-Newtonian Bio-Bi-Phase Flow Due to Peristaltic Transport of Particulate Fluid
}

\author{
Sudheer Khan ${ }^{1, *}$, Shu Wang ${ }^{1}$ \\ College of Applied Science, Beijing University of Technology, Beijing 100124, P.R. China
}

\section{ARTICLE INFO}

\section{Article history:}

Received 5 December 2020

Received in revised form 27 January 2021

Accepted 28 January 2021

Available online 15 March 2021

\section{Keywords:}

Bio-bi-phase flow; electro-magnetohydrodynamics; particulate fluid; peristaltic flow

\section{ABSTRACT}

The present article aims to probe the impacts of electro-magneto-hydrodynamics (EMHD) peristaltic flow of in-compressible, dusty, non-Newtonian fluid in a hose of predetermined dimension together with homogeneously scattered analogous rigid particles. In the presence of transversal static magnetic field, Navier-Stokes's equations are employed to design a flow problem for the particulate phase. Governing flow problem is simplified by approximation of long wavelength and zero Reynolds number. The analytical solution for both velocities (solid-liquid) and pressure rise is computed by using well known computational software Mathematica. Perturbation method is employed to extract analytical solution of the resulting ordinary differential equations. Impacts of different physical parameters, expansion in trapped bolus for fluid and particulate velocity profile by increasing Hartmann number are displayed and explained through graphs. Furthermore, a rise in skin friction is noticed with the rise in particle effect and electro-osmotic parameter. This study may have greater significance and viable applications to improve the quality of micro-fluidic devices.

\section{Introduction}

Fluid transport has fundamental importance in innovative world of fluid mechanics. Researchers are keenly interested in this special zealous area in response of its wider applications in medical equipment e.g., medical sensors, biological systems like blood flow, urine transport, sweating, biochips, micro pumps, industrial and engineering fields. One of the special phenomena of physiological flow can be observed in esophagus, ureter, chyme drive in the intestinal tract, sperm movement in male generative system and flowing of blood through arteries. This physiological special flow type is termed as Peristalsis. This peristaltic movement produced in the fluid by the contracting and relaxing muscular movement of the flexible tube-like structure containing fluid. This interesting flow mechanism works in living organisms as an inbuilt system while researchers have embraced with its man-made applications in biomedical engineering e.g., heart-lung machines, finger pumps, dialysis machine, and roller pump. Many significant uses of this flow procedure can be observed at larger scale e.g., transportation of slurries, fluid like sanitary, corrosive and noxious in nuclear industry.

\footnotetext{
* Corresponding author.

E-mail address: soudkayani@hotmail.com
} 
Practical application of this phenomenon in biochemical systems and industries is peristaltic pumping by means of finger and roller pumps to push corrosive or pure material by special care to prevent fluid adherence with internal surface of pump [1-5]. Study of this special aspect of fluid flow is initiated by Latham [6] to comprehend the peristaltic streams of hydrodynamic fluids with significant hypothetical and experimental soundings assuming different parameters i.e., low Reynolds number, long wavelength, small wave amplitude etc.

In recent time, too much progress has seen in the study of micro and nanofluidic. Nanotechnology along with peristaltic flow has brought modernization in present science and technology world. Inventions and applications like microelectronics, nuclear reactor coolant, hybrid power engines, space technology, fuel cells and pharmaceutical processes grinding are best descriptions of its technological importance. The theme "nanofluid" was principally familiarized by Choi [7] with probing about the improvement standard of thermal conducting ability of low or non-conducting fluids. investigated the peristaltic flow for the Jeffrey fluid model of chime in the small intestine using a magnetic field. Later workflow is added by Akbar et al., [8,9]. They introduced the induced magnetic field environment in an asymmetric channel and gave numerical observations for peristaltic fluid flow. Stud et al., [10] explored the blood flow with moving magnetic field to observe the influence of magnetic field. Human blood constitutes a suspension of red blood cells and can behave as an electronically conducting fluid. This philosophical idea was given by Srivastava and Agrawal [11]. Anwaruddin et al., [12] considered peristaltic flow of blood in between flexible wall channel to construct a mathematical model for magnetic field effects by applying a wavelength approximation method. In biological context, fluid flow through curved type geometry of flexible and compliant ducts and granular tubes. Inspiring by this natural curved characteristic of peristaltic flow, number of investigations for peristaltic movement can be seen by researchers in compliant (flexible) walls channels/tubes $[13,14]$. Kumari et al., [15] observed the peristaltic flow inside a channel with some inclination and wall effects and explained the magnetic field and slip behavior. Aly et al., [16,17] encountered the slip effects for temperature, concentration and velocity of nanofluid with asymmetric wave production on walls of channel and extract analytical exact solution. Dramatical rise is noticed in the importance of multiphase flow from years. Reza-E-Rabbi et al., [18] studied multiphase flow involving nano sized particles and analyzed the hydrodynamic flow behavior. Casson nanofluid flow over an elongating pane together with magnetohydrodynamics (MHD) has been elaborated for heat a mass transfer analysis [19]. Significant result-oriented work in the same sequence of heat and mass transfer analysis can be noticed in studies [20-27].

Studies associated with heat transmission and flow of particulate fluids in a channel are intensely advantageous in several engineering and industrial devices to ameliorate the designing and functioning purposes. Numerous very useful execution is discussed in, polymer technology, fluid droplet sprays, refining of crude oil in the petroleum industry and electrostatic precipitation [28-33]. In the presence of magnetic field acting in transverse direction, electrically conducting and particulate fluid flows are also revolutionized through various applications such as flow meters, pumps, generators and accelerators. Usually, the compact particles in such devices are dangled as soot in the conducting fluid due to combustion and corrosion processes. Investigations about the proven and practical significance of solid particles in efficient working principal of these devices attained much attention of researchers [34-36].

Micro-electric mechanical system is surprisingly greater development in mixed scientific industries due to its innovative applications e.g., Lab-on-a-chip. Ionized liquid flow in a microchannel subject to the conditions like tangential external electric field and stationary charged walls of channel is referred as electro-osmotic flow. The micro-pumps based on the mechanism of electro-osmosis has major constituent role in Lab-on-a-chip. The scientific innovation has been made in the micro- 
scale projects with the expansion in microfluidics devices, micro pumping and peristaltic micro pumping [37]. Without depending on mechanical parts, pulse free and plug-like flow production of electro-osmotic micro-pumps is its greater assistance [38]. Various important paybacks like liquid chromatography, fluid stirring and mixing, flow control in fluidic networks, fluid pumping etc. are based on the EMHD behavior of fluid are popular among researchers [39-41].

Interactions phenomenon amid the fluid and particle phase, particle-particle phase, and particlewall introduce Solid liquid fluidized bed (SLFB) systems. Higher heat and mass transfer rates of SLFB systems raises their importance in industry and wide usage significance in chemicals, food industries, biochemical, mineral processing, and involving variety of applications such as ion exchange, water treatment, separation of minerals, sedimentation, adsorption, and crystallization. Shakhaoath et al., [42] generated an investigation over liquid fluidized beds based on segregation and dispersion of binary particle species of different densities and uniform size. Comparative study and review of published work about SLFB was organized by Shakhaoath et al., [43].

Innovative approaches of EMHD micro-pumps got huge attentions in current innovative world. Numerous authors have studied the effects of EMHD peristaltic flow of non-Newtonian incompressible dusty fluids $[44,45]$. However, bi-phase peristaltic motion of fluid under influence of an electromagnetic field has not been yet scrutinized. The current study is initiated in this sequence to make precise observations on the peristaltic flow of two-phase fluid and the impression of EMHD in a channel of finite length with the assumption of long wavelength. Governing flow problem is simplified by approximation of Long wavelength and zero Reynolds number. The analytical solution for both velocities (solid-liquid) and pressure rise is computed by using well known computational software Mathematica. Perturbation method is employed to extract analytical solution of the resulting ordinary differential equations. Next to literature review the propound study is furnished as: transport equations and flow analysis is stated in Section 2; solution methodologies are presented in Section 3. The justification of numerical and graphical outcomes is elaborated in Section 4. Finally, essential remarks are communicated in the endmost Section. The effect of all the physical parameters is drawn for the fluid phase velocity, the particulate phase velocity and pressure difference. The streamline graphs disclose the expansion in trapped bolus for fluid and particulate velocity profile by increasing Hartmann number. Furthermore, a rise in skin friction is noticed with the rise in particle effect and electro-osmotic parameter.

\section{Formulation of the Problem}

Consider an unsteady, incompressible and electrically conducting particle fluid suspension exhibiting a peristaltic movement along a channel of finite length. The two-dimensional incompressible fluid flow is subject to the conditions: electrokinetic body force is functional in the axial direction and a uniform magnetic field is acting in the transverse direction. The behaviour of fluid is considered electrically conducting due to the effect of electric and magnetic field (Figure 1). Mathematical representation of the geometrical model in Figure 1 is as

$H(X, t)=a+b \sin \frac{2 \pi}{\lambda}(X-c t)$

The governing equations for fluid phase and particulate phase in terms of the Cartesian coordinate system $(X, Y)$ are of the form. 


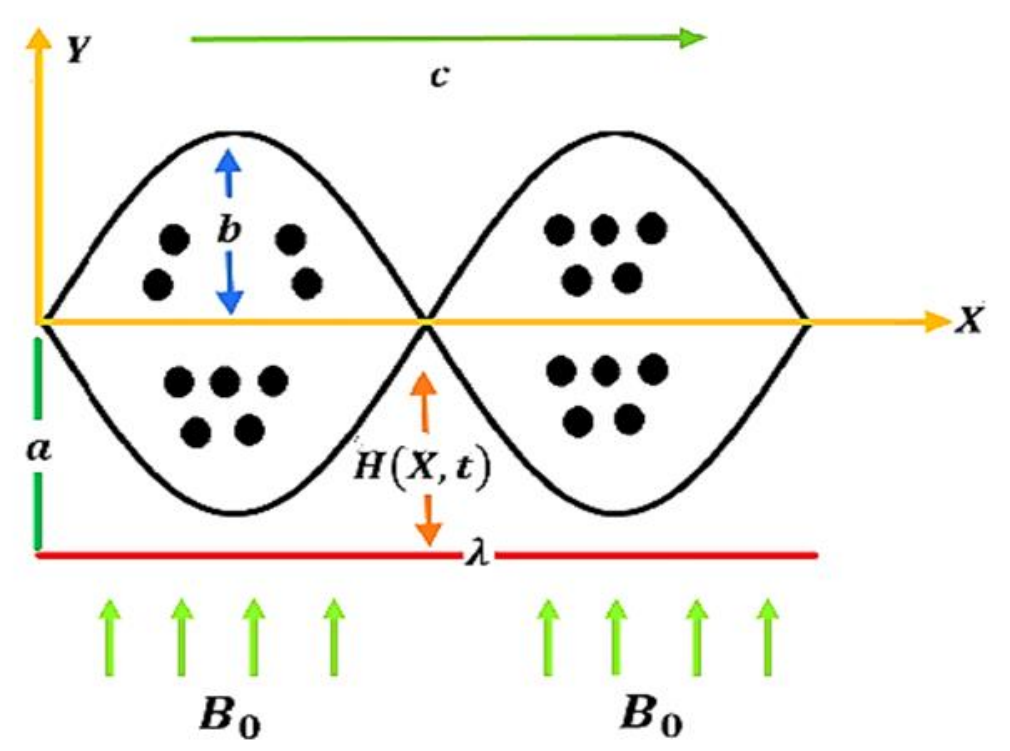

Fig. 1. Geometry of the problem

\subsection{System of Equations for Fluid Phase}

$\frac{\partial U_{f}}{\partial X}+\frac{\partial V_{f}}{\partial Y}=0$

$(1-C) \rho_{f}\left\{\frac{\partial U_{f}}{\partial t}+U_{f} \frac{\partial U_{f}}{\partial X}+V_{f} \frac{\partial U_{f}}{\partial Y}\right\}=-(1-C) \frac{\partial P}{\partial X}+(1-C) \mu_{S}\left(\frac{\partial^{2} U_{f}}{\partial X^{2}}+\frac{\partial^{2} U_{f}}{\partial Y^{2}}\right)+C S\left(U_{p}-U_{f}\right)+$ $\bar{\rho}_{e} E_{X}+\vec{J} \times \vec{B}$,

$(1-C) \rho_{f}\left\{\frac{\partial V_{f}}{\partial t}+U_{f} \frac{\partial V_{f}}{\partial X}+V_{f} \frac{\partial V_{f}}{\partial Y}\right\}=-(1-C) \frac{\partial P}{\partial Y}+(1-C) \mu_{S}\left(\frac{\partial^{2} V_{f}}{\partial X^{2}}+\frac{\partial^{2} V_{f}}{\partial Y^{2}}\right)+\vec{\rho}_{e} E_{Y}+C S\left(V_{p}-V_{f}\right)$

\subsection{System of Equations for Particulate Phase}

$\frac{\partial U_{p}}{\partial X}+\frac{\partial V_{p}}{\partial Y}=0$

$C \rho_{p}\left\{\frac{\partial U_{p}}{\partial t}+U_{p} \frac{\partial U_{p}}{\partial X}+V_{p} \frac{\partial U_{p}}{\partial Y}\right\}=-C \frac{\partial P}{\partial X}+C S\left(U_{f}-U_{p}\right)$,

$C \rho_{p}\left\{\frac{\partial V_{p}}{\partial t}+U_{p} \frac{\partial V_{p}}{\partial X}+V_{p} \frac{\partial V_{p}}{\partial Y}\right\}=-C \frac{\partial P}{\partial Y}+C S\left(V_{f}-V_{p}\right)$

\section{Solution of the Problem}

Using non-dimensional parameter

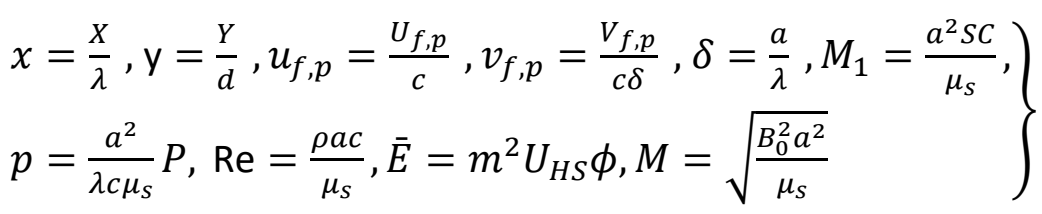


Using the Eq. (8), in Eq. (1)-(6), and taking the approximation of low Reynolds number and long wavelength after some simplification we get the resulting equation of fluid phase as

$\frac{\partial p}{\partial x}=\frac{\partial^{2} u_{f}}{\partial y^{2}}-\frac{m^{2}}{1-C} U_{H S} \phi+\frac{M_{1}}{1-C}\left(u_{p}-u_{f}\right)-\frac{H a^{2}}{1-C} u_{f}$,

$\frac{\partial p}{\partial y}=0$

And for particulate phase

$\frac{\partial p}{\partial x}=\frac{M_{1}}{C}\left(u_{f}-u_{p}\right)$

$\frac{\partial p}{\partial y}=0$

The Second order slip conditions are

$$
\begin{aligned}
& u=-U_{\text {slip }}=-\left(A \frac{\partial u}{\partial y}+B \frac{\partial^{2} u}{\partial y^{2}}\right) \text { at } \mathrm{y}=0, \\
& u=U_{\text {slip }}=A \frac{\partial u}{\partial y}+B \frac{\partial^{2} u}{\partial y^{2}} \text { at } \mathrm{y}=\mathrm{h},
\end{aligned}
$$

where $A=\frac{2}{3}\left(\frac{3-\alpha l^{3}}{\alpha}-\frac{3}{2} \frac{1-l^{2}}{k_{n}}\right)$ and $B=-\frac{1}{4}\left(l^{4}+\frac{2\left(1-l^{2}\right)}{k_{n}{ }^{2}}\right) \frac{\lambda}{a^{2}}$.

Series solution for fluid and dust phase are

$$
\begin{aligned}
& U_{f}=C_{1} \operatorname{Cosh} \frac{H a y}{\sqrt{1-C}}+C_{2} \operatorname{Sinh} \frac{H a y}{\sqrt{1-C}}-\frac{(1-C)}{H a^{2}}\left(1-\frac{C}{1-C}\right) \frac{\partial p}{\partial x}+\frac{(1-C) m^{2} U_{H S}}{m^{2}(1-C)-H a^{2}} \phi \\
& U_{p}=C_{1} \operatorname{Cosh} \frac{H a y}{\sqrt{1-C}}+C_{2} \operatorname{Sinh} \frac{H a y}{\sqrt{1-C}}-\frac{(1-C)}{H a^{2}}\left(1-\frac{C}{1-C}\right) \frac{\partial p}{\partial x}+\frac{(1-C) m^{2} U_{H S}}{m^{2}(1-C)-H a^{2}} \phi-\frac{C}{M_{1}} \frac{\partial p}{\partial x}
\end{aligned}
$$

where,

$$
\begin{aligned}
& C_{1}=\frac{1}{1+\frac{B H a^{2}}{1-C}}\left(\frac{(1-C)\left(1-\frac{C}{1-C}\right) \frac{\partial p}{\partial x}}{H a^{2}}-\frac{(1-C) m^{2} U_{H S} \operatorname{Sech}[h m]}{-H a^{2}+(1-C) m^{2}}-\frac{B(1-C) m^{4} U_{H S} \operatorname{Sech}[h m]}{-H a^{2}+(1-C) m^{2}}-\frac{\left(A H a^{2}\left(T_{1}+\frac{P_{1}}{Q_{1}}\right)\right)}{R_{1}}\right) \\
& C_{2}=\frac{(1-C)\left(1-\frac{C}{1-C}\right) \frac{\partial p}{\partial x}}{H a^{2}}-\frac{(1-C) m^{2} U_{H S}}{-H a^{2}+(1-C) m^{2}}-\frac{B(1-C) m^{4} U_{H S}}{-H a^{2}+(1-C) m^{2}}-P_{2}+\frac{Q_{2}}{R_{2}}
\end{aligned}
$$

Here $C_{1}$ and $C_{2}$ are integration constants. To synopsize the volume of equation we have considered

$$
\begin{aligned}
& T_{1}=\frac{(1-C)\left(1-\frac{C}{1-C}\right)}{H a^{2}}+\frac{(1-C) m^{2} U_{H S}}{-H a^{2}+(1-C) m^{2}}-\frac{(1-C) m^{4} U_{H S}}{-H a^{2}+(1-C) m^{2}}-\frac{1}{H a^{2}+\frac{B H a^{2}}{1-C}}(1-C)(1- \\
& \left.\frac{C}{1-C}\right) \frac{\partial p}{\partial x}\left(-\operatorname{Cosh}\left[\frac{h H a^{2}}{\sqrt{1-C}}\right]\right)+\frac{B H a^{2} \operatorname{Cosh}\left[\frac{h H a^{2}}{\sqrt{1-C}}\right]}{1-C}+\frac{A H a^{2} \operatorname{Sinh}\left[\frac{h H a^{2}}{\sqrt{1-C}}\right]}{\sqrt{1-C}}
\end{aligned}
$$




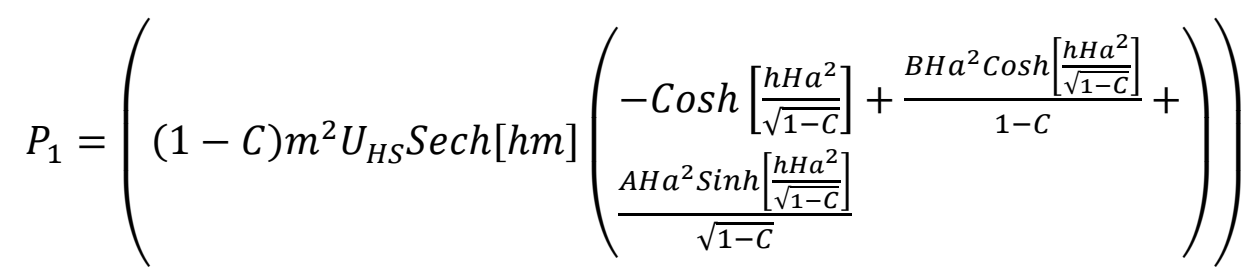

$Q_{1}=\left(\left(1+\frac{B H a^{2}}{1-C}\right)\left(-H a^{2}+(1-C) m^{2}\right)\right)+\frac{\left(B(1-C) m^{4} U_{H S} \operatorname{Sech}[h m]\left(\begin{array}{l}-\operatorname{Cosh}\left[\frac{h H a^{2}}{\sqrt{1-C}}\right] \\ \frac{B H a^{2} \operatorname{Cosh}\left[\frac{h H a^{2}}{\sqrt{1-C}}\right]}{1-C}+ \\ \frac{A H a^{2} \sinh \left[\frac{h H a^{2}}{\sqrt{1-C}}\right]}{\sqrt{1-C}}\end{array}\right)\right)}{\left(\left(1+\frac{B H a^{2}}{1-C}\right)\left(-H a^{2}+(1-C) m^{2}\right)\right)-\frac{A(1-C) m^{3} U_{H S} T a n[h m]}{-H a^{2}+(1-C) m^{2}}}$

$R_{1}=\sqrt{1-C}\left(\begin{array}{l}\frac{A H a^{2} \operatorname{Sinh}\left[\frac{h H a^{2}}{\sqrt{1-C}}\right]}{\sqrt{1-C}}-\operatorname{Sinh}\left[\frac{h H a^{2}}{\sqrt{1-C}}\right]+\frac{B H a^{2} \operatorname{Sinh}\left[\frac{h H a^{2}}{\sqrt{1-C}}\right]}{1-C}- \\ \frac{A H a^{2}\left(\begin{array}{l}-\operatorname{Cosh}\left[\frac{h H a^{2}}{\sqrt{1-C}}\right]+\frac{B H a^{2} \operatorname{Cosh}\left[\frac{h H a^{2}}{\sqrt{1-C}}\right]}{1-C}+ \\ \frac{A H a^{2} \operatorname{Sinh}\left[\frac{h H a^{2}}{\sqrt{1-C}}\right]}{\sqrt{1-C}}\end{array}\right)}{\sqrt{1-C}\left(1+\frac{B H a^{2}}{1-C}\right)}\end{array}\right)$

$P_{2}=\frac{1}{H a^{2}+\frac{B H a^{2}}{1-C}}(1-C)\left(1-\frac{C}{1-C}\right) \frac{\partial p}{\partial x}\left(-\operatorname{Cosh}\left[\frac{h H a^{2}}{\sqrt{1-C}}\right]+\frac{B H a^{2} \operatorname{Cosh}\left[\frac{h H a^{2}}{\sqrt{1-C}}\right]}{1-C}+\frac{A H a^{2} \operatorname{Sinh}\left[\frac{h H a^{2}}{\sqrt{1-C}}\right]}{\sqrt{1-C}}\right)$

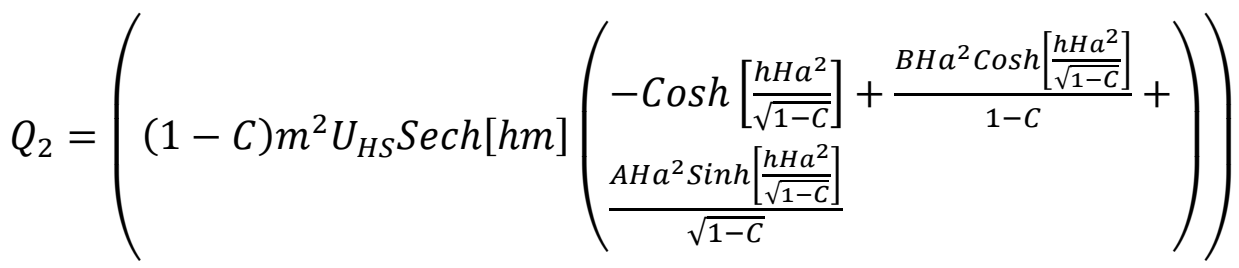

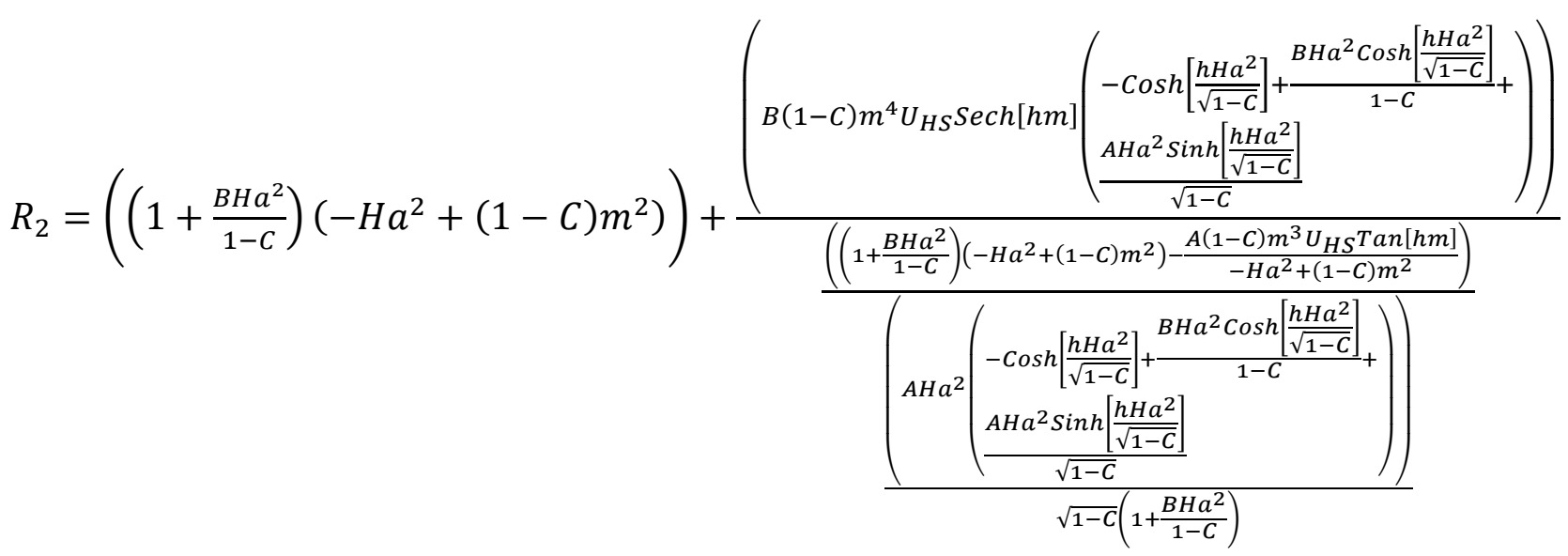




\section{Results and Discussion}

This section contains the graphical portrayal of different parameters sketched by computational software Mathematica and discussion of analytical solution. The solutions of velocity, pressure, streamlines for fluid and particulate phase are elaborated graphically through various pertinent parameters like Hartmann number $(\mathrm{Ha})$, particle effect $(\mathrm{C})$ and Electro-osmotic parameter $(\mathrm{m})$ with second-order slip conditions. The computational software Mathematica has been used to visualize the performance of all the parameters through graphs.

Figure 2-4 represents the behaviour of velocity profiles of fluid phase and Figure 5-7 represents the behaviour of velocity profiles of particle-phase along with different parameters with the variations of time.

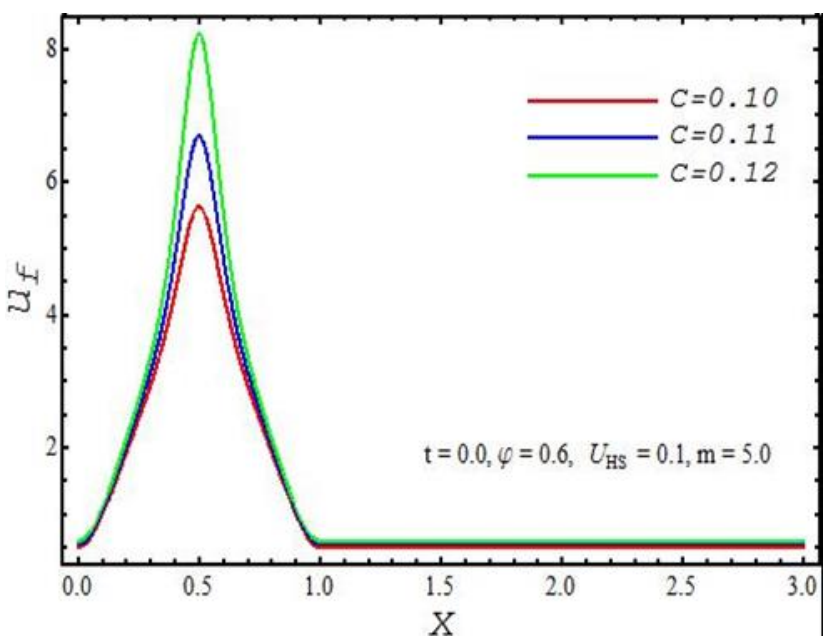

(a)

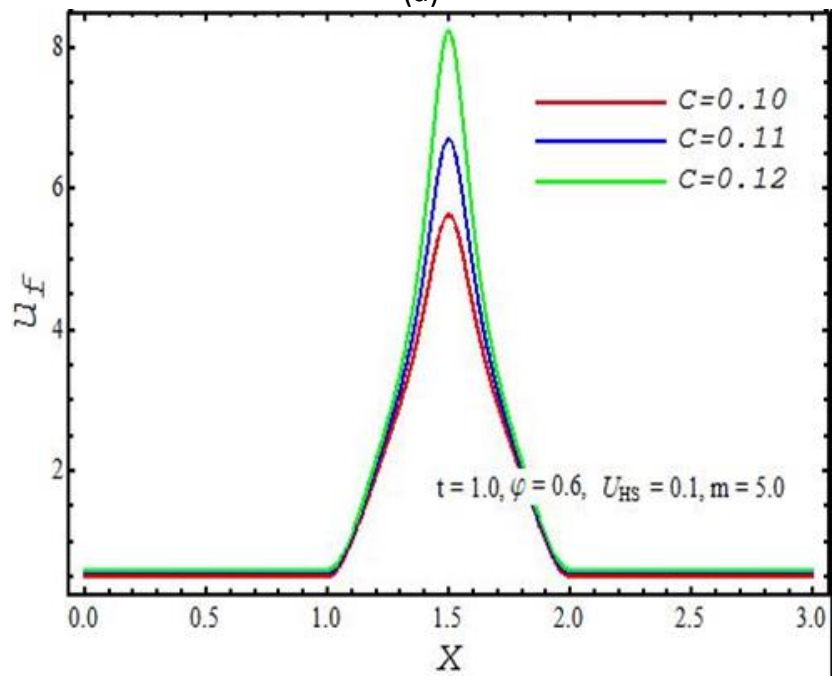

(c)

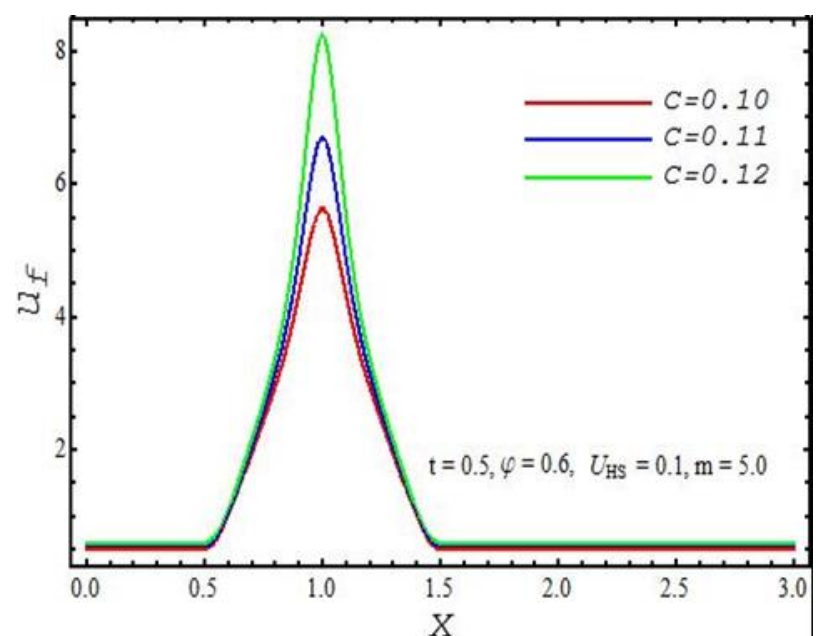

(b)

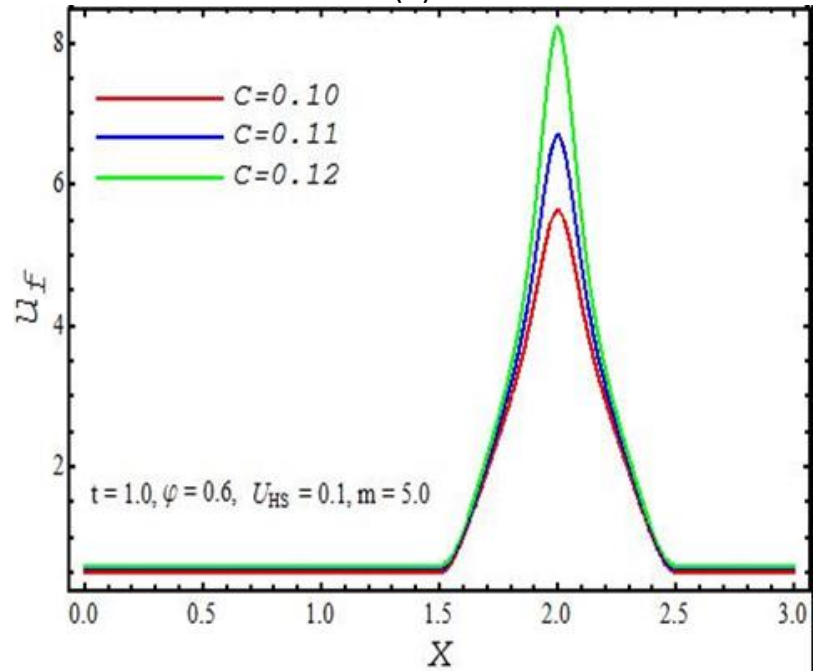

(d)

Fig. 2. Velocity for fluid phase at various values of $\mathrm{C}(\mathrm{a}) \mathrm{t}=0$, (b) $\mathrm{t}=0.5$, (c) $\mathrm{t}=1.0$, (d) $\mathrm{t}=1.5, \varphi=0.6, U_{H S}=$ $0.1, m=5$ 
Figure 2 declares that the velocity profile of the fluid phase shows the relationship between velocity and particle effect $(C)$. It depicts that velocity of fluid phase decreases with the variations of particle effect $(C)$ due to resistive drag force which is induced due to the presence of particles, whereas velocity profile of particulate phase shows opposite behaviour as shown in Figure 5 . Figure 3 reveals that the velocity profile of the fluid phase increases with increase in Hartmann number due to the influence of Lorentz force which resists the flow. The velocity contour of the particulate phase demonstrates the opposite behaviour in Figure 6.

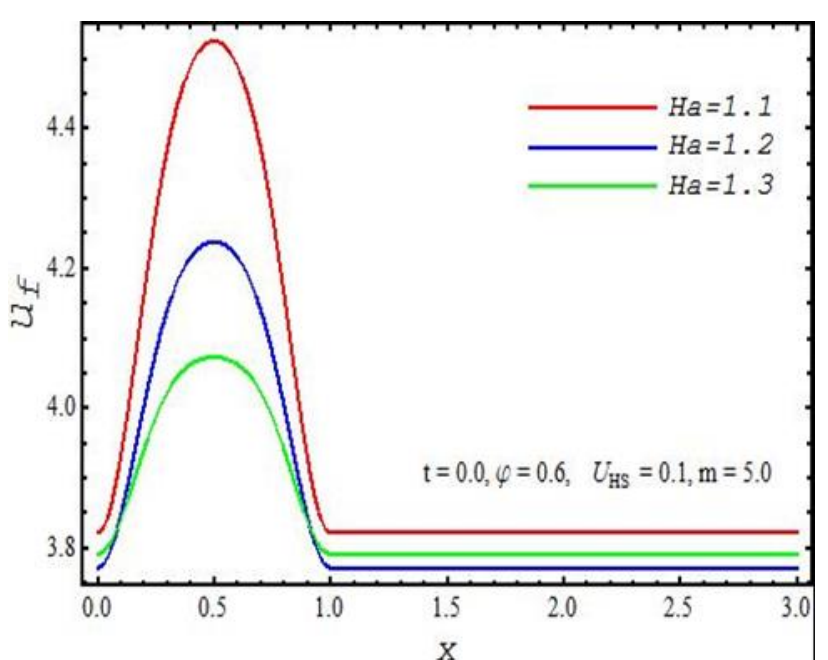

(a)

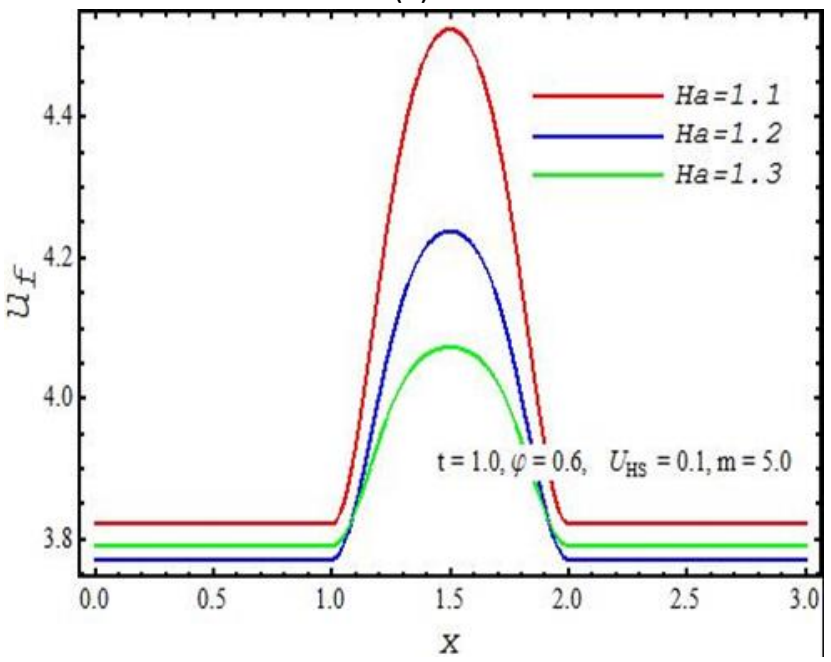

(c)

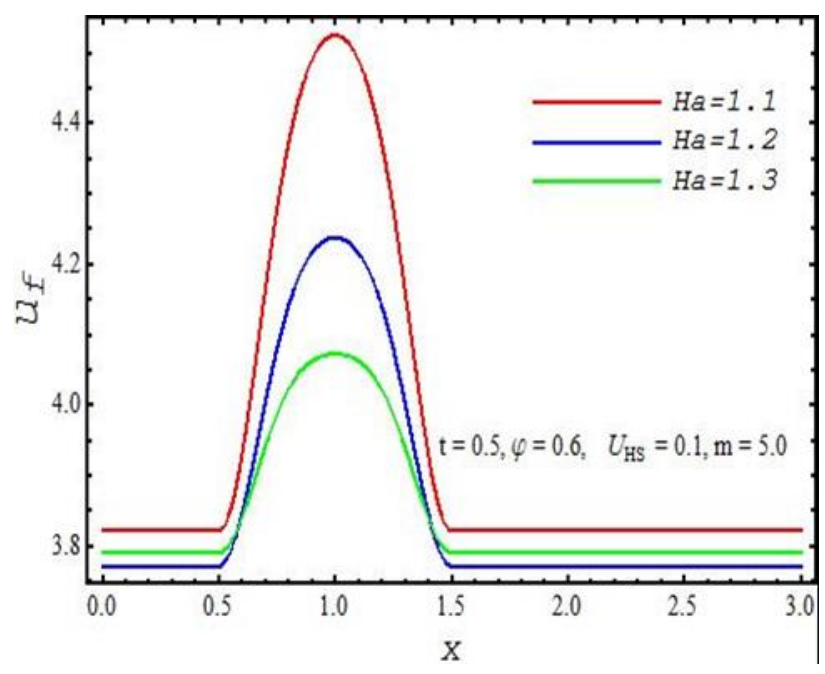

(b)

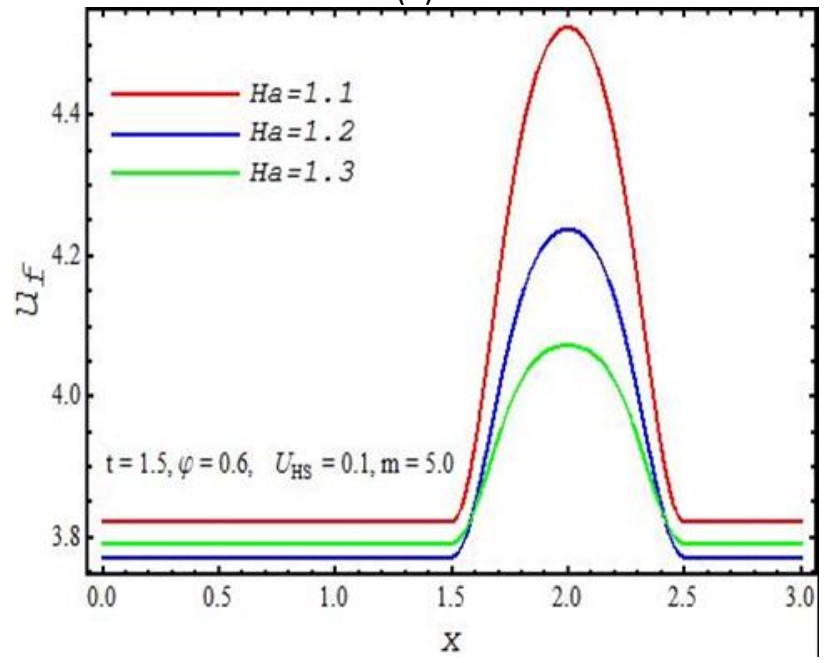

(d)

Fig. 3. Graph for velocity at various values of $\mathrm{Ha}$. (a) $t=0$, (b) $t=0.5$, (c) $t=1.0$, (d) $t=1.5$, when $\varphi=$ $0.6, U_{H S}=0.1, m=5$ 
Figure 4 indicates that increase in electro-osmotic parameter $(m)$ reflects a decline in velocity profile graph. The parameter $(m)$ is inversely proportional to Debye length. The velocity profile of the particulate phase shows the opposite behaviour as displayed in Figure 7 . There is no effect on the graphs even the variation of time. All graphs show same result at different time.

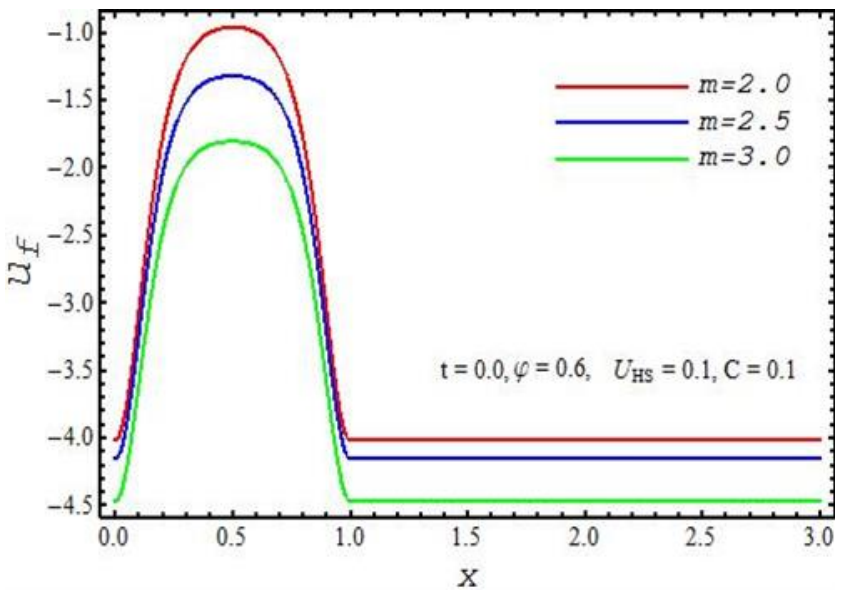

(a)

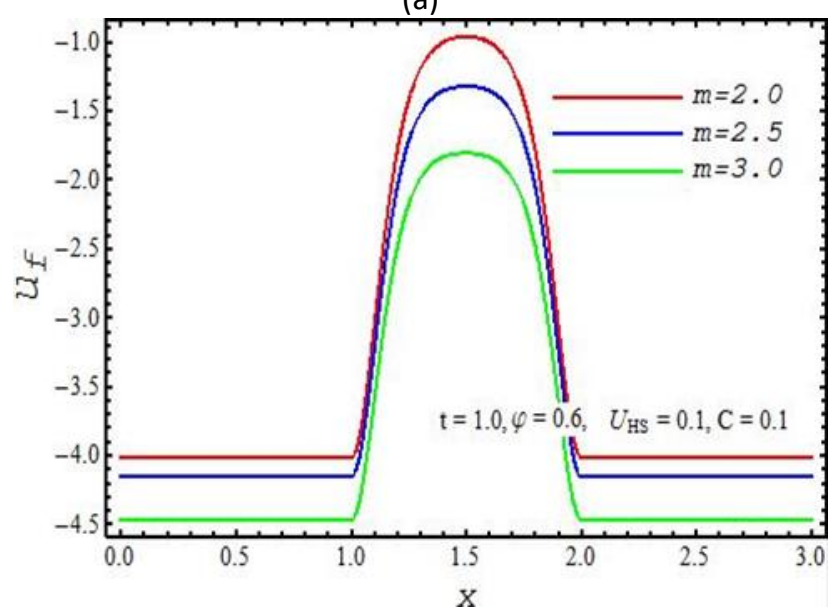

(c)

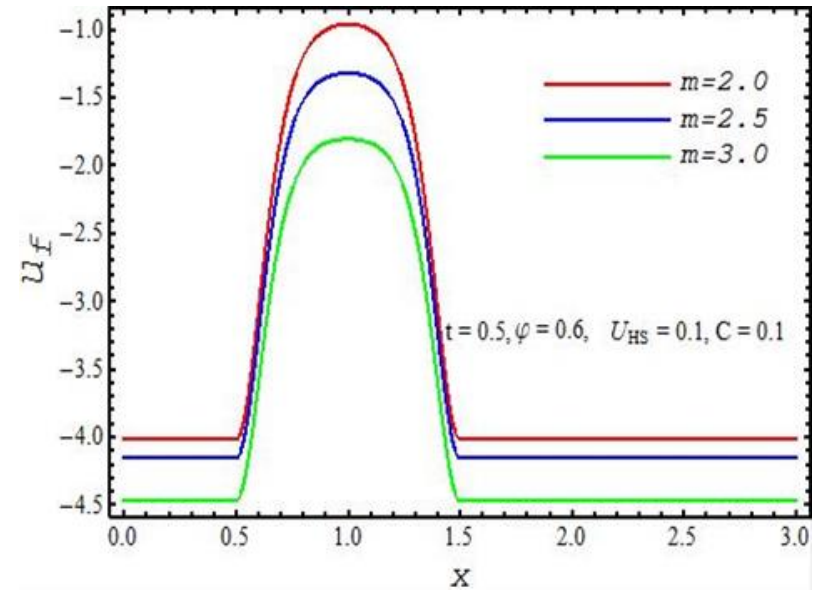

(b)

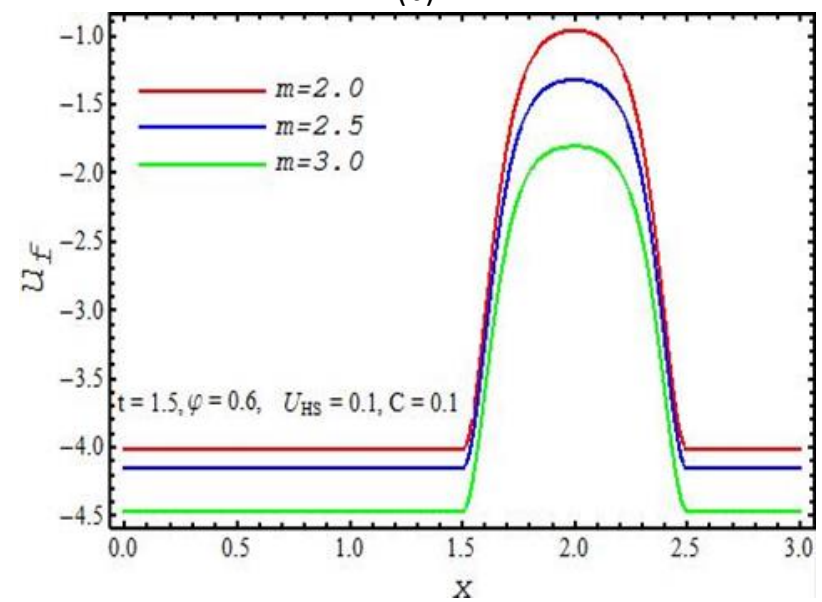

(d)

Fig. 4. For various values of $m$, the graph represents velocity for (a) $t=0$, (b) $t=0.5$, (c) $t=1.0$, (d) $t=1.5$, when $\varphi=0.6, U_{H S}=0.1, C=0.1$ 


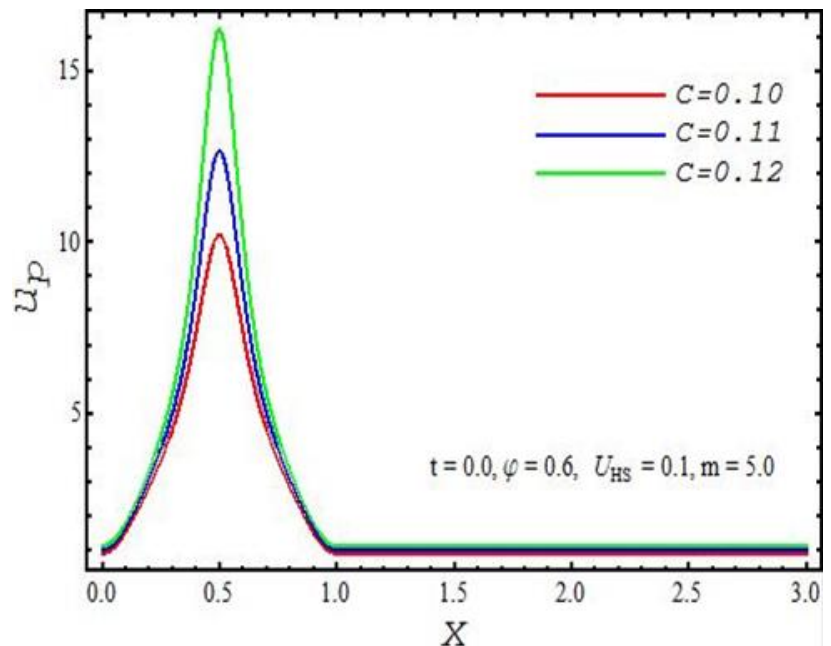

(a)

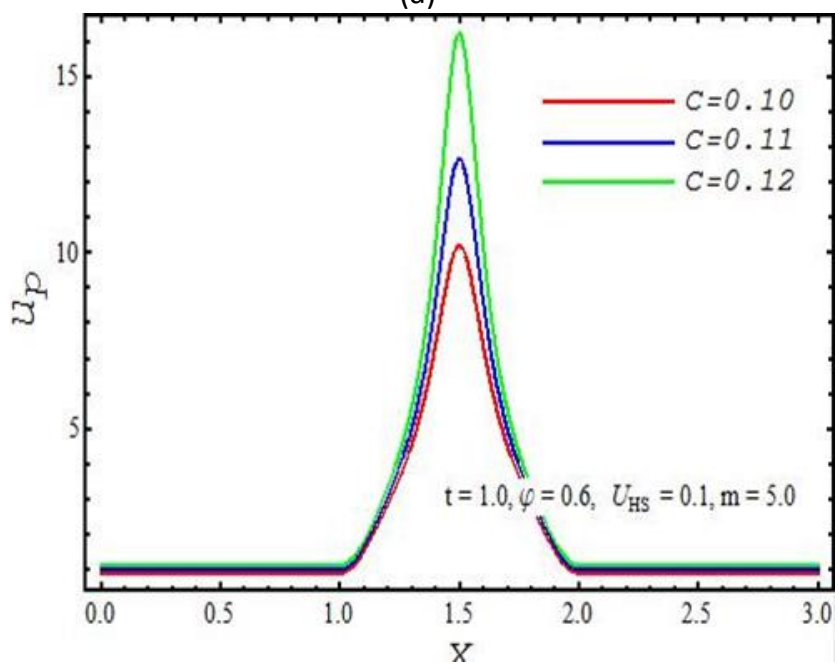

(c)

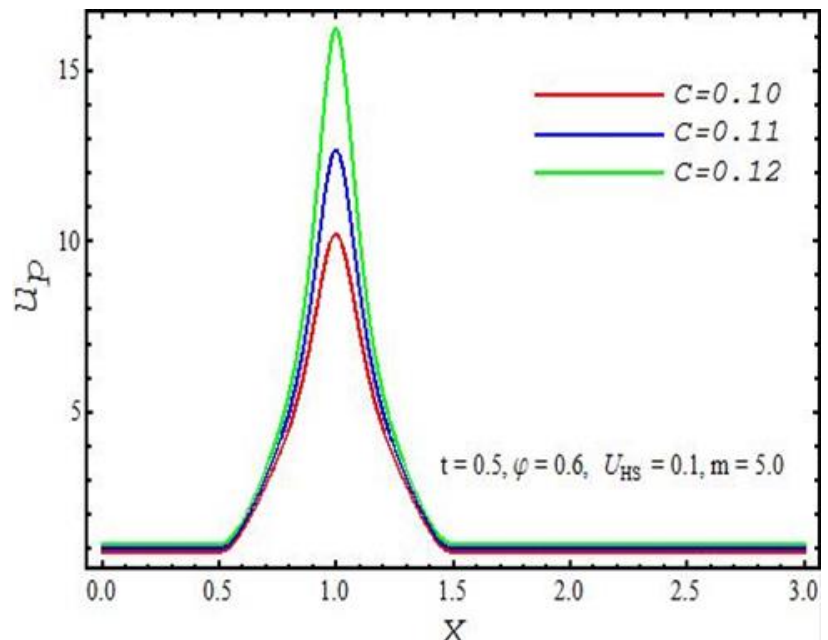

(b)

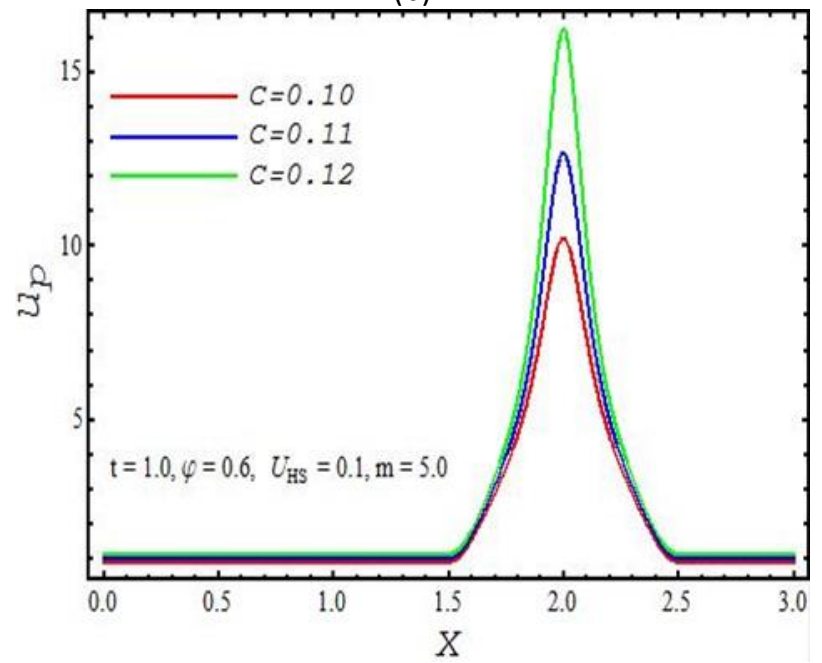

(d)

Fig. 5. Velocity graph for particulate phase at various values of $C$ below (a) $t=0,(b) t=0.5$, (c) $t=1.0$, (d) $t$ $=1.5$, when $\varphi=0.6, U_{H S}=0.1, m=5$ 


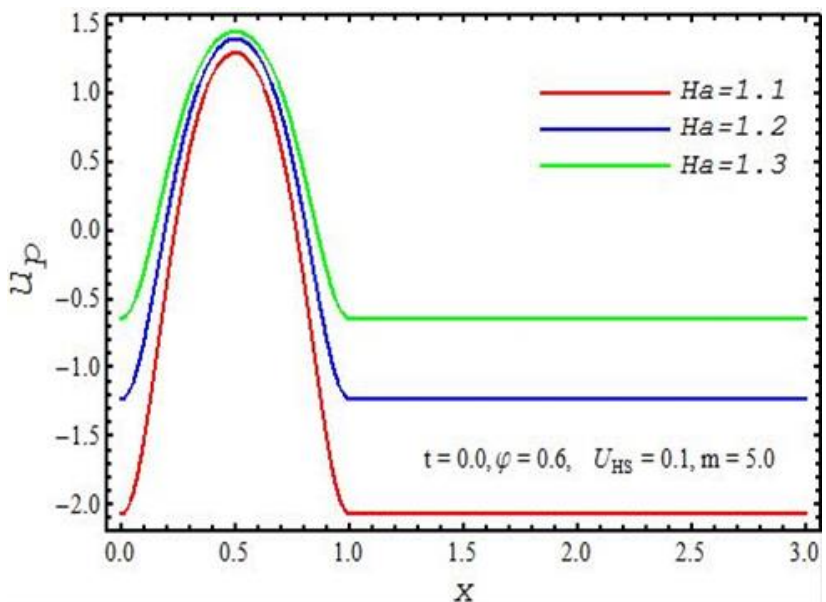

(a)

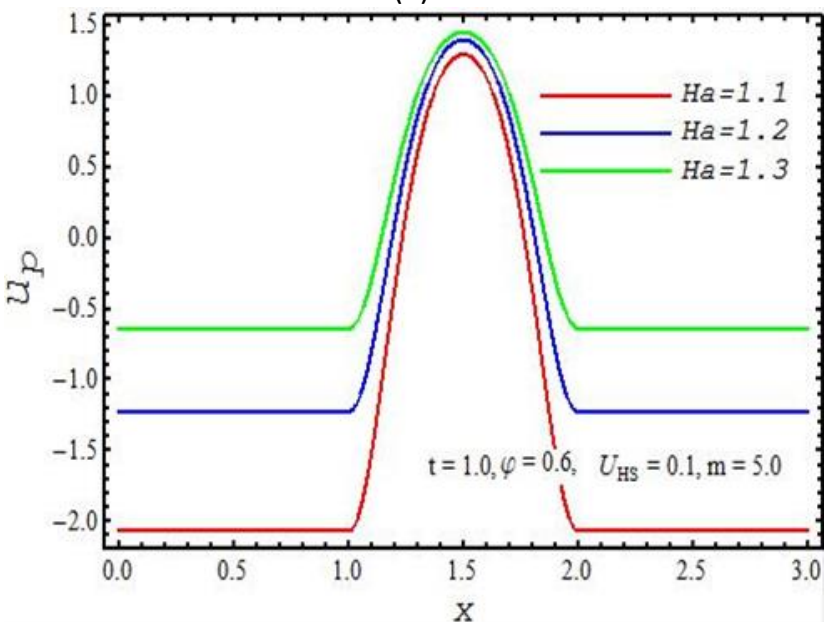

(c)

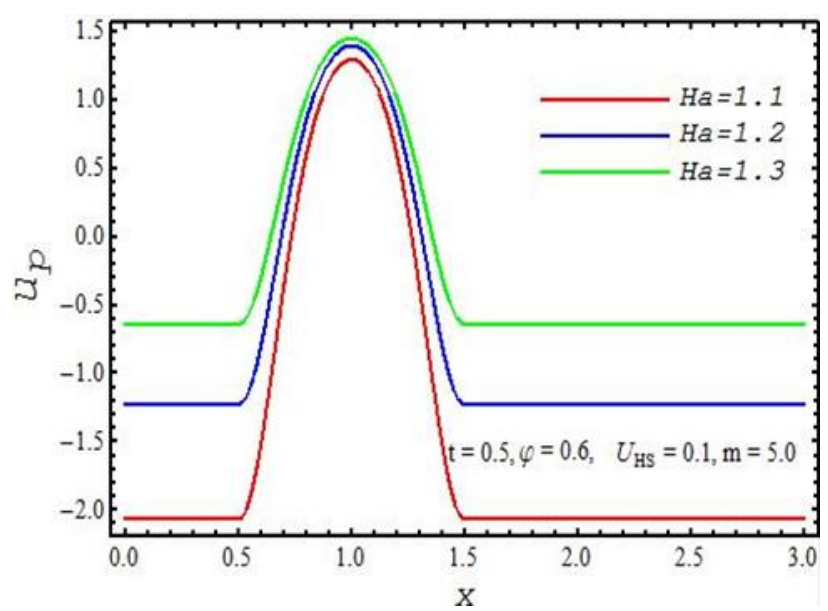

(b)

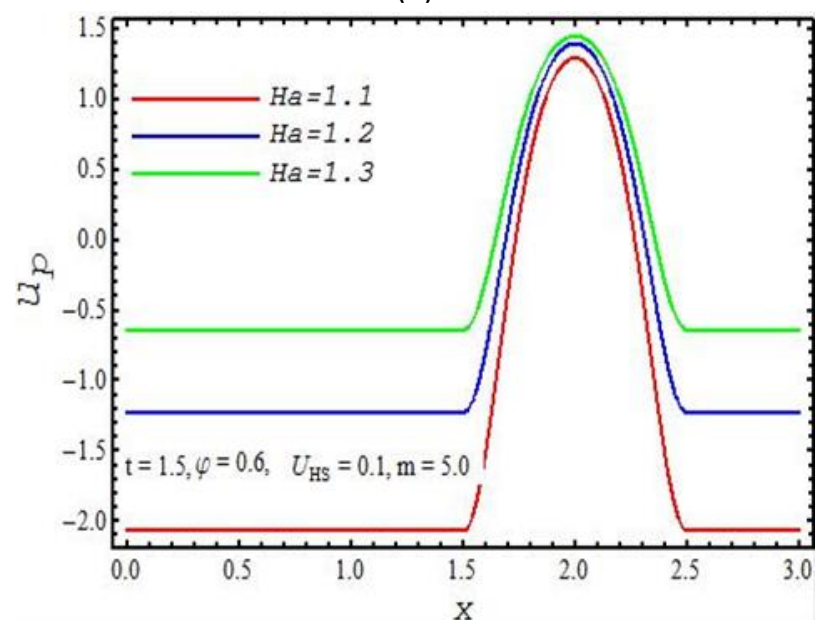

(d)

Fig. 6. Graph for velocity at particulate phase with various values of $\mathrm{Ha}(\mathrm{a}) \mathrm{t}=0$, (b) $t=0.5$, (c) $t=1.0$, (d) $t=$ 1.5 , when $\varphi=0.6, U_{H S}=0.1, m=5$ 


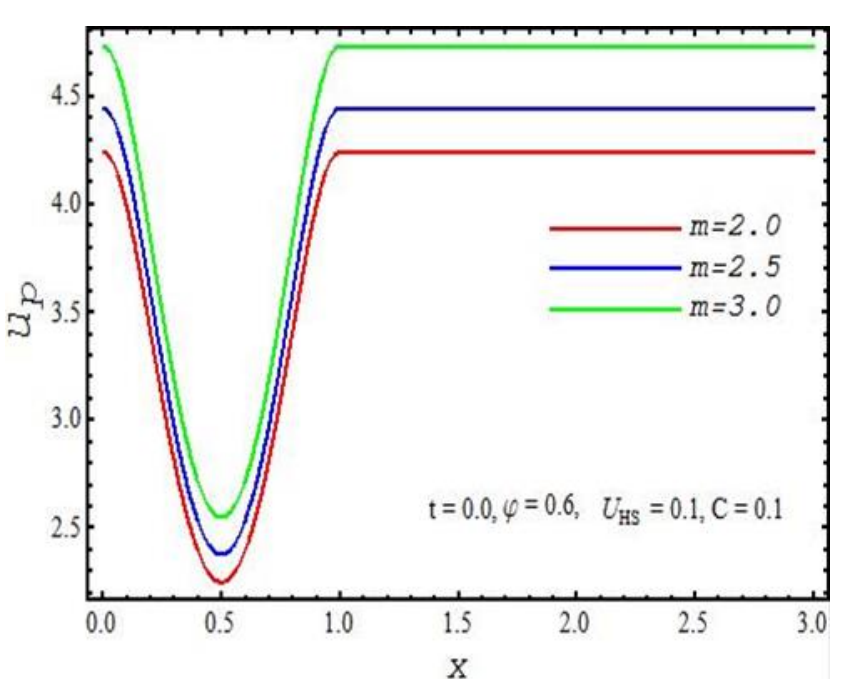

(a)

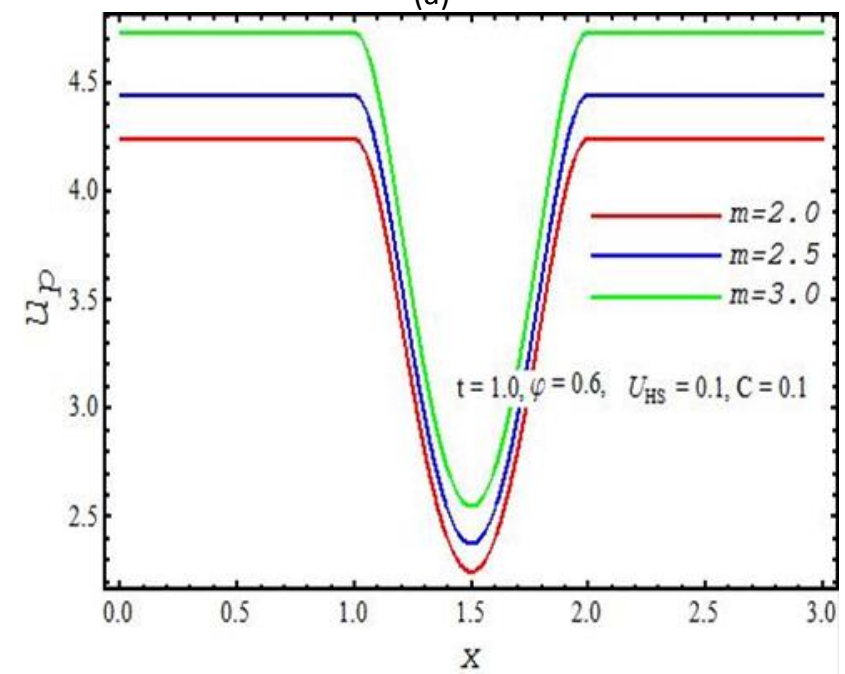

(c)

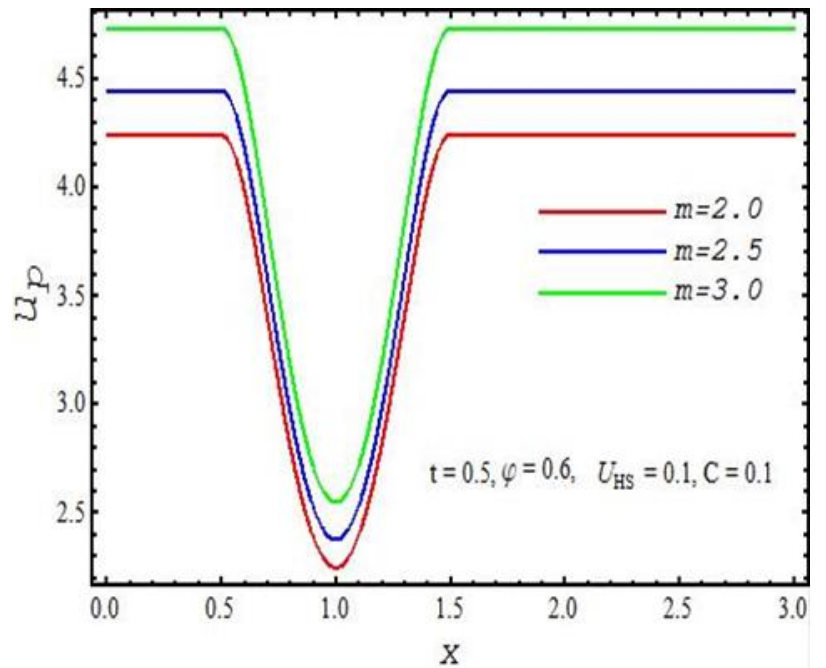

(b)

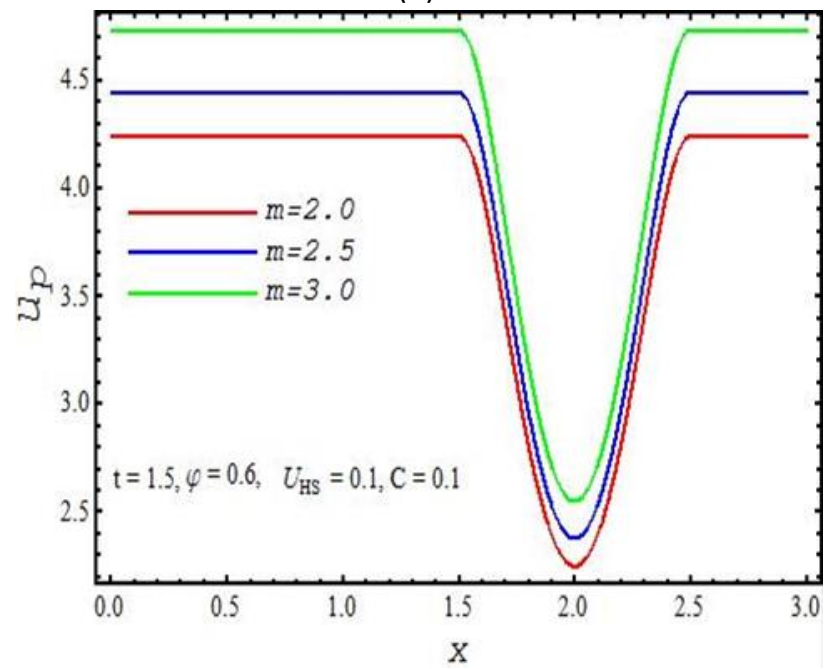

(d)

Fig. 7. Velocity representation for the particulate phase at various values of $m(a) t=0,(b) t=0.5,(c) t=1.0$, (d) $\mathrm{t}=1.5$, when $\varphi=0.6, U_{H S}=0.1, C=0.1$

Figure 8-10 represent the influence of the pressure gradient for different parameters with the variations of time. The relation between velocity and particle effect $(C)$ is shown in Figure 8 . A rise in pressure graph is noticed with the rise in values of particle effect (C). Similarly, Figure 9 and 10 shows the increase in pressure graphs with the increase of Hartmann number $(\mathrm{Ha})$ and electro-osmotic parameter $(\mathrm{m})$. 


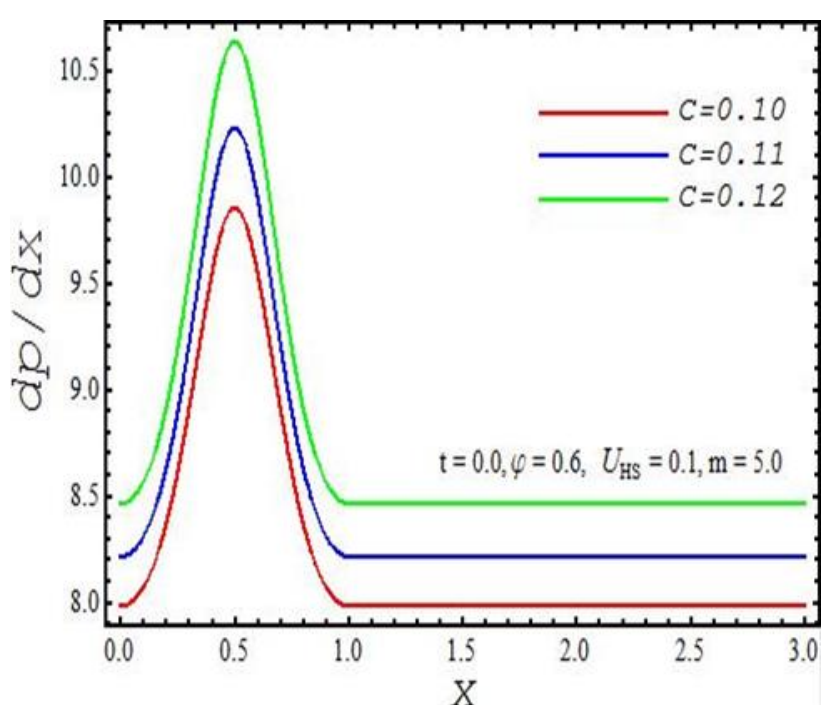

(a)

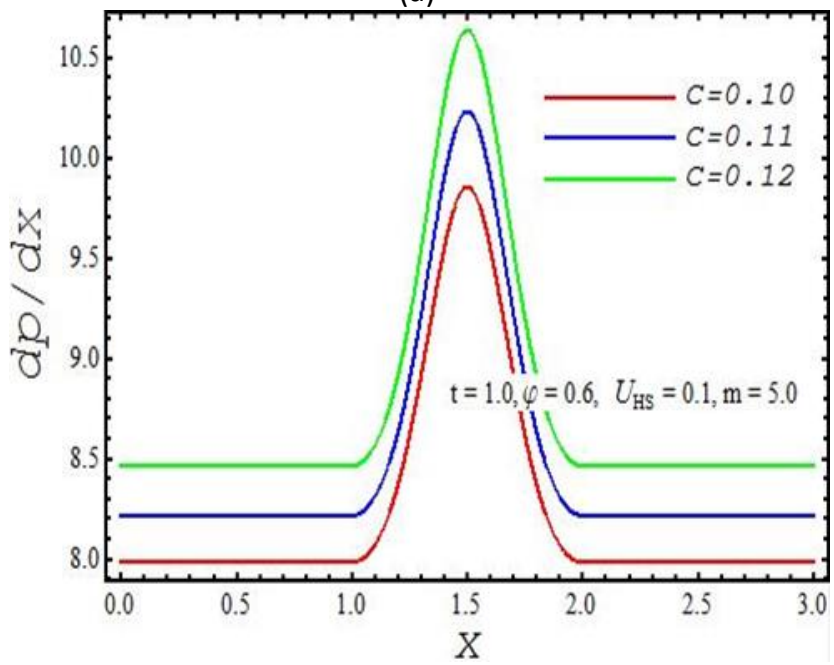

(c)

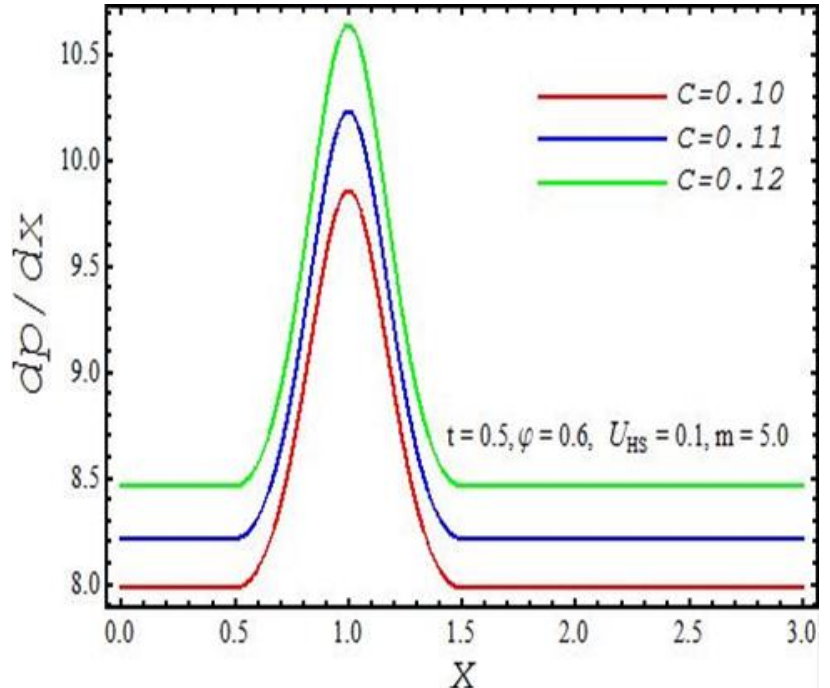

(b)

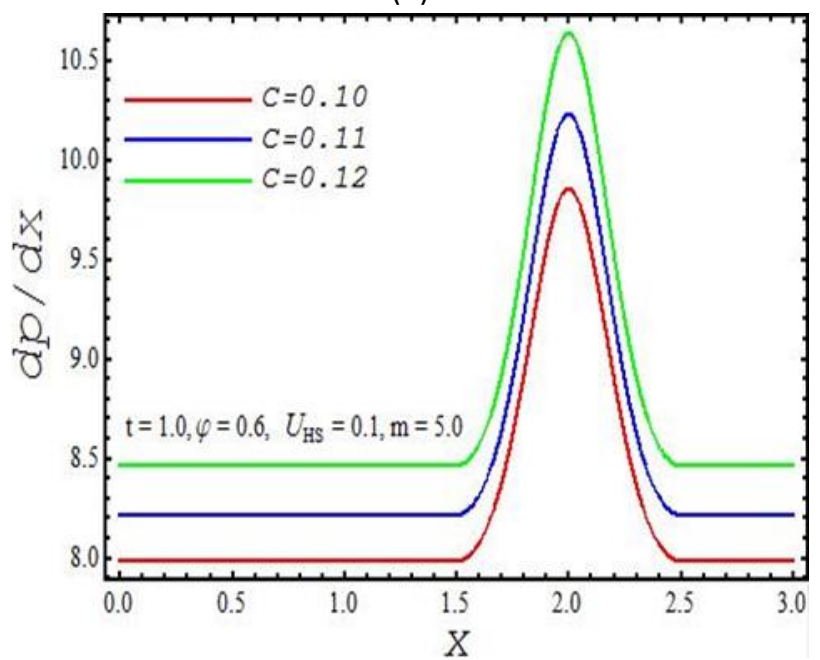

(d)

Fig. 8. Pressure gradient at various values of $\mathrm{C}$ for (a) $\mathrm{t}=0$, (b) $\mathrm{t}=0.5$, (c) $\mathrm{t}=1.0$, (d) $\mathrm{t}=1.5$, when $\varphi=$ $0.6, U_{H S}=0.1, m=5$ 


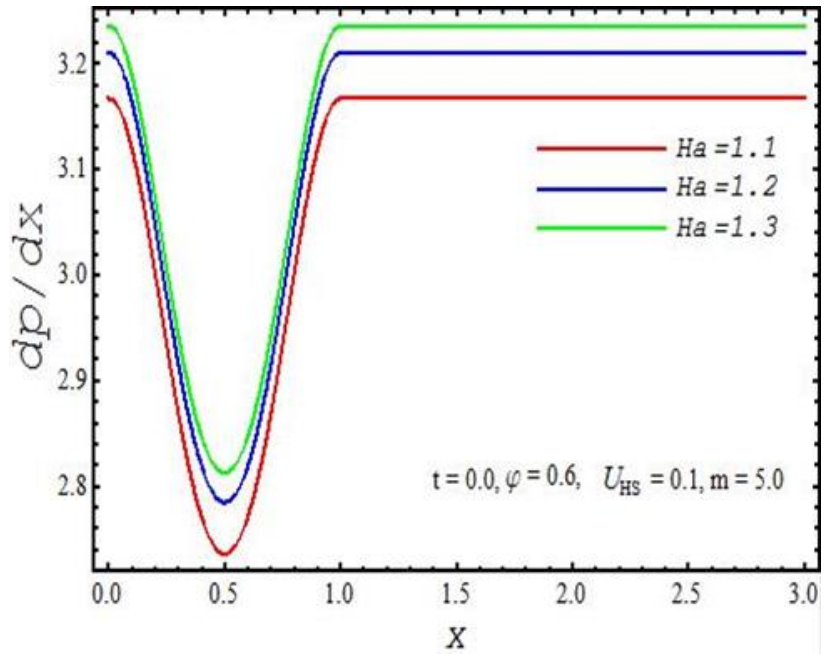

(a)

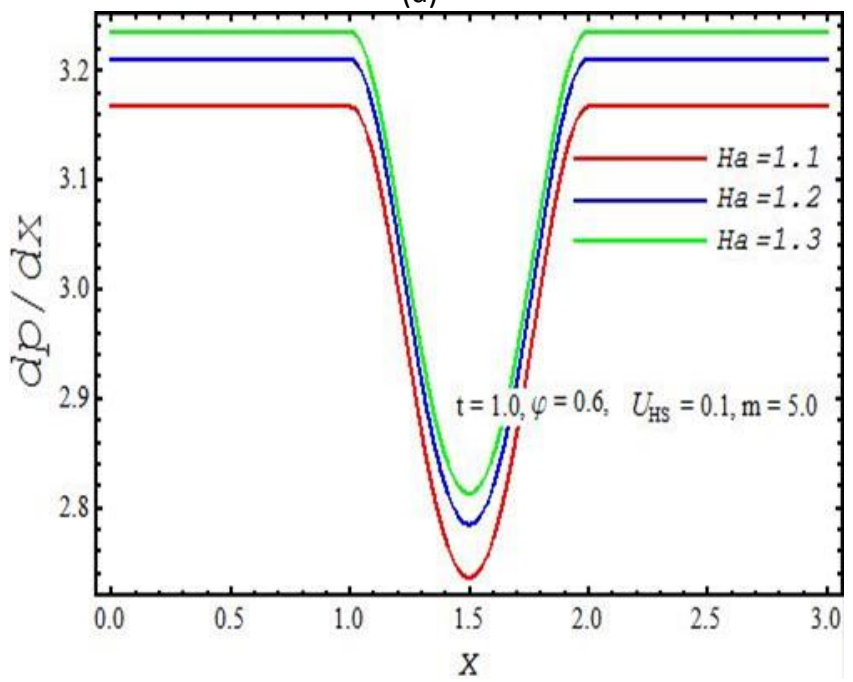

(c)

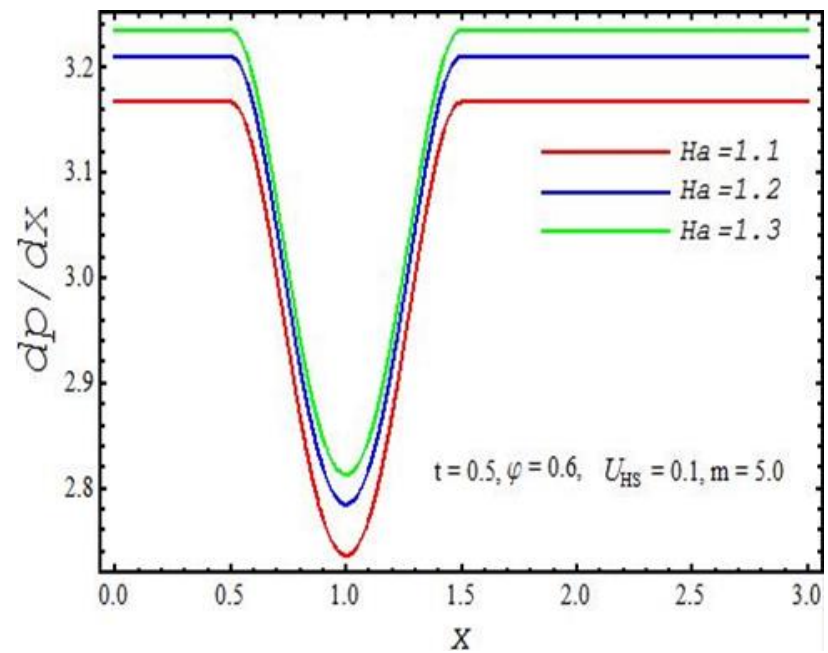

(b)

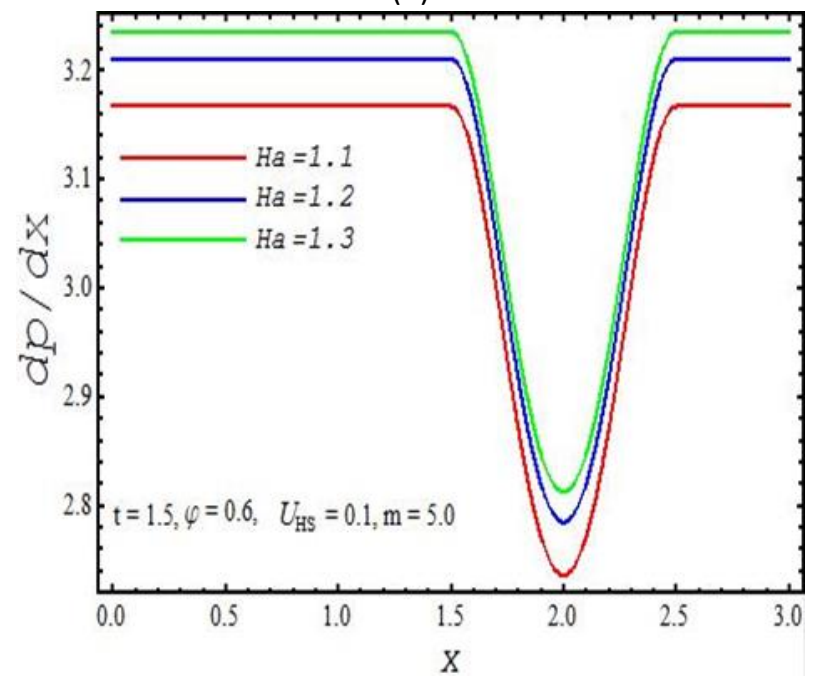

(d)

Fig. 9. Pressure gradient at different values of $\mathrm{Ha}$ in (a) $t=0$, (b) $t=0.5$, (c) $t=1.0$, (d) $t=1.5$, when $\varphi=$ $0.6, U_{H S}=0.1, C=0.1$ 


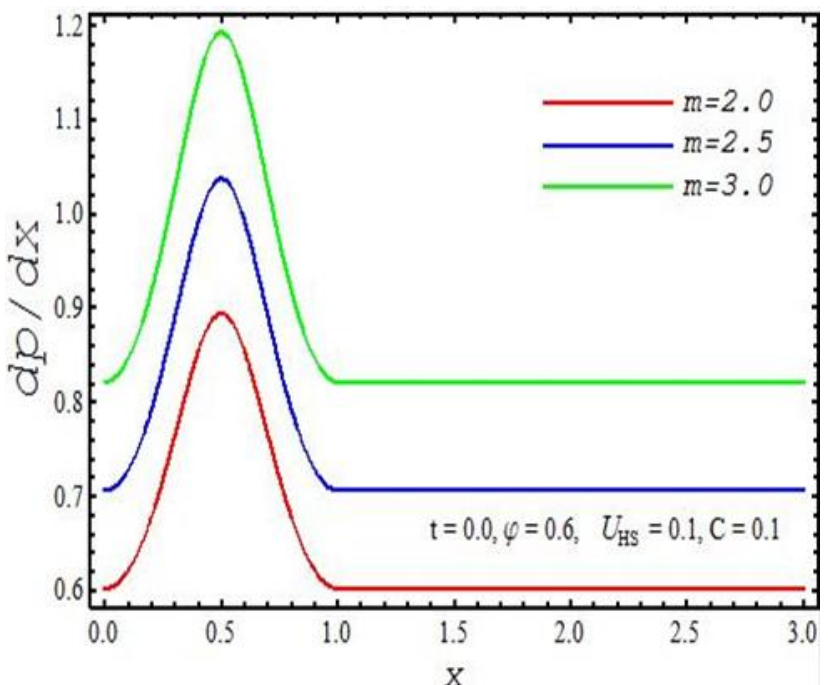

(a)

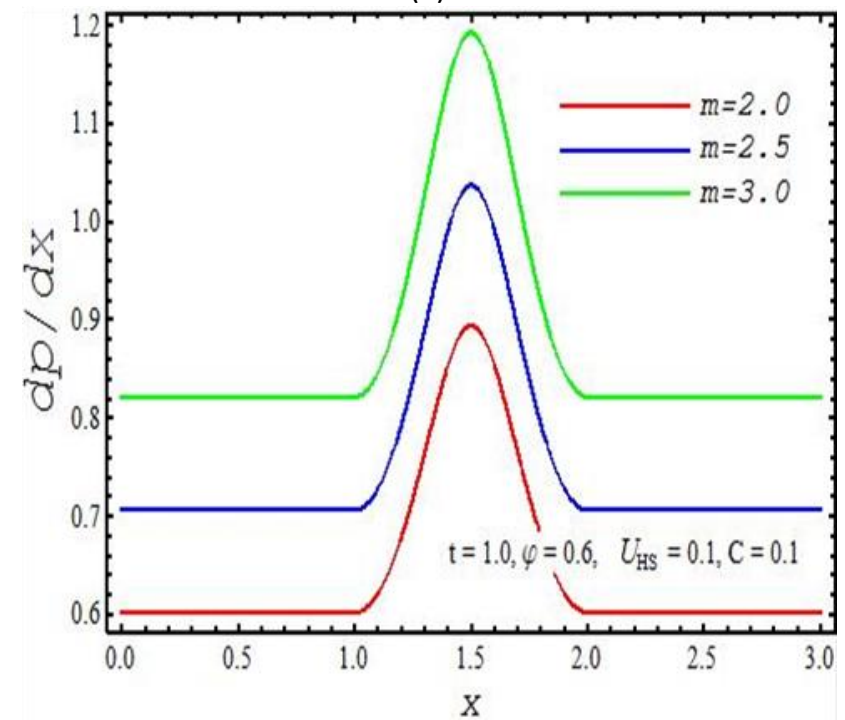

(c)

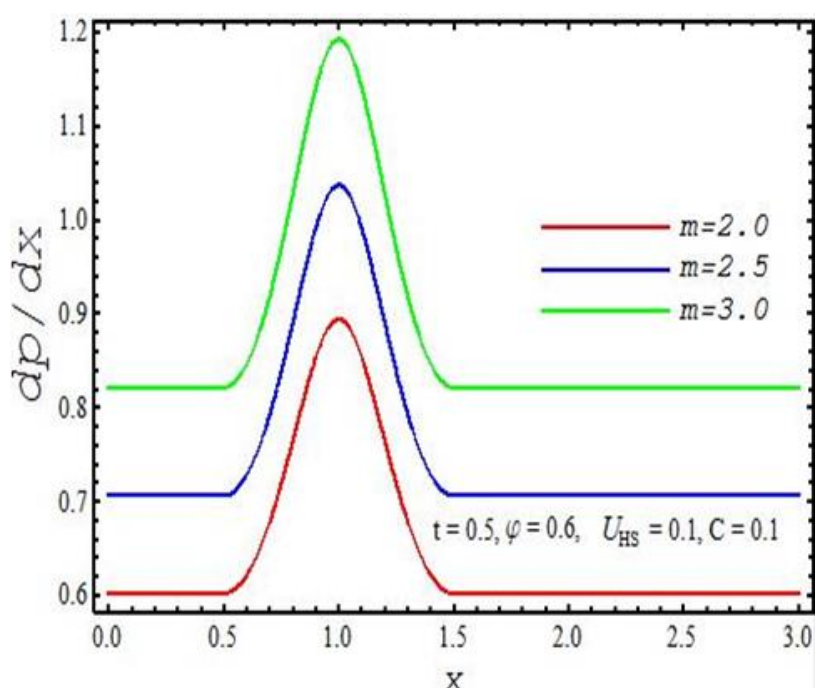

(b)

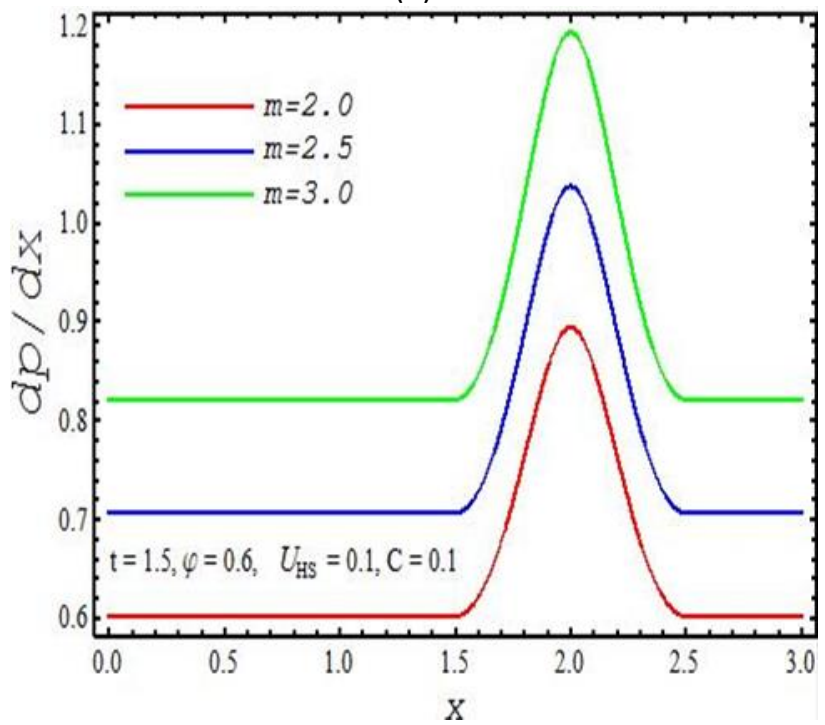

(d)

Fig. 10. Pressure gradient at various values of $m$ below (a) $t=0$, (b) $t=0.5$, (c) $t=1.0$, (d) $t=1.5$, when $\varphi=$ $0.6, U_{H S}=0.1, C=0.1$

Figure 11 and 12 represents the role of skin friction with the variations of Hartmann number $(\mathrm{Ha})$ along with different values of particle effect $(C)$ and Electro-osmotic parameter $(m)$ respectively. It can be seen from Figure 4-11 that by increasing the values of both particle effect $(C)$ and Hartmann number $(\mathrm{Ha})$, graph gradually increases. Graph of skin friction at different values of particle effect $(C)$ starts from the same point and shows the same behaviour. Figure 12 indicates that by increasing the value of electro-osmotic $(m)$, Hartmann number $(\mathrm{Ha})$ is increased Skin friction graphs at different values of $m$ starts from different points but shows the same trend. 


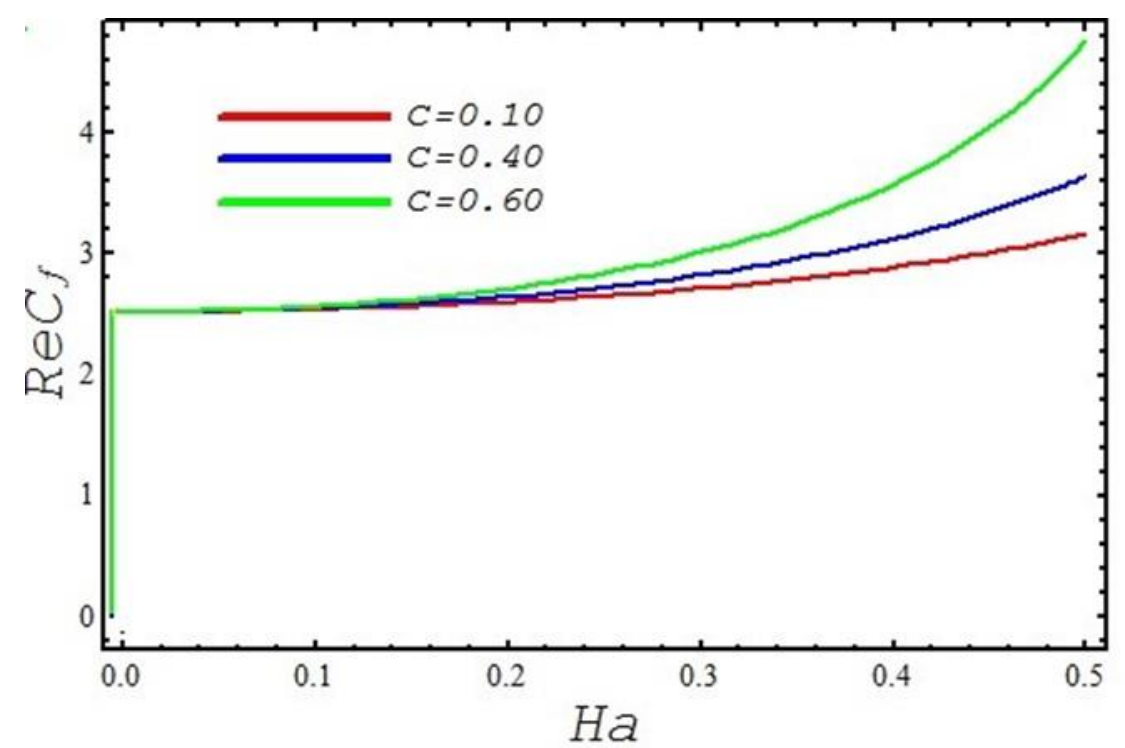

Fig. 11. Skin friction at various values of $\mathrm{C}$, when $\varphi=0.6, U_{H S}=$ $1, m=5$

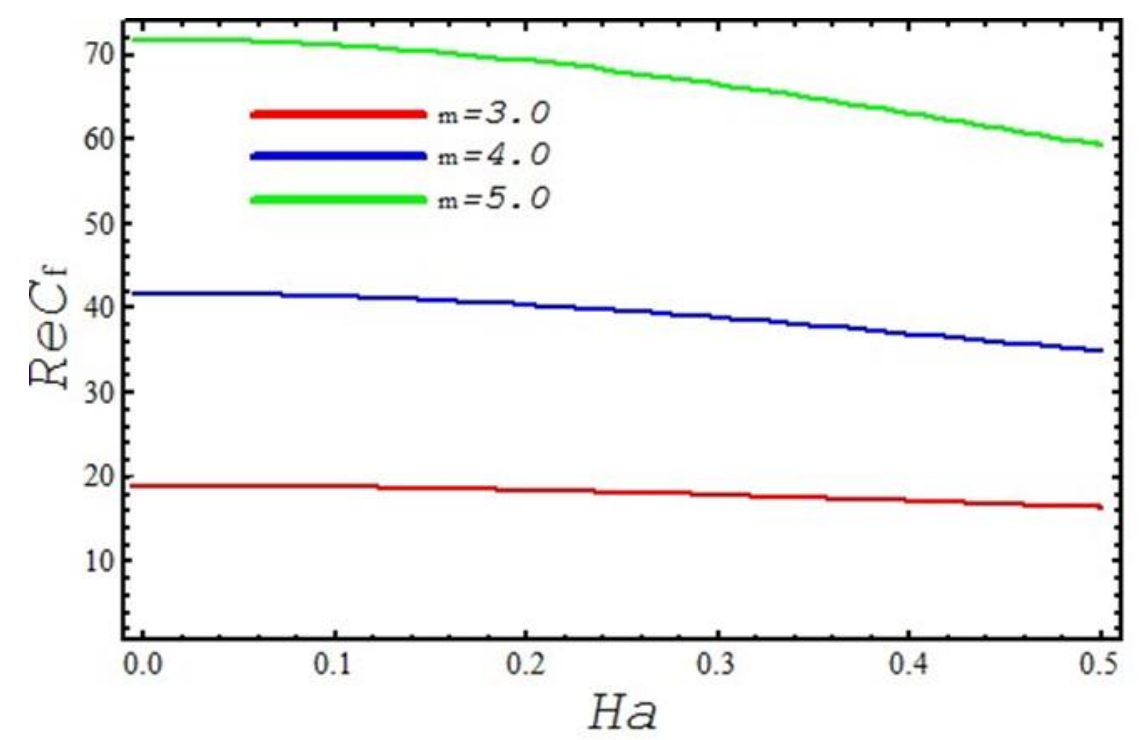

Fig. 12. Skin friction at various values of $\mathrm{m}$, when $\varphi=0.6, U_{H S}=1, C=$ 0.1

Figure 13 (a)-(d) and Figure 14 (a)-(d) shows the behaviour of streamlines by using the different values of Hartmann number $(\mathrm{Ha})$ along with the fixed set of other parameters in the fluid and particulate phase. Closed streamlines circulating bolus of fluid is formed. In Figure 13 (a)-(d) of the fluid phase, the bolus forms in trapped geometry when Hartmann number $(\mathrm{Ha})$ is low. It is observed that by increasing the value of Hartmann number $(\mathrm{Ha})$ the trapped bolus starts expanding.

It can be seen that in Figure 14 (a)-(d) of the particulate phase, the trapped bolus comes with a small value of Hartmann number $(\mathrm{Ha})$ and it starts expanding with increasing value of Hartmann number $(\mathrm{Ha})$. The graphs disclose the expansion in trapped bolus for fluid and particulate velocity profile by increasing Hartmann number. 


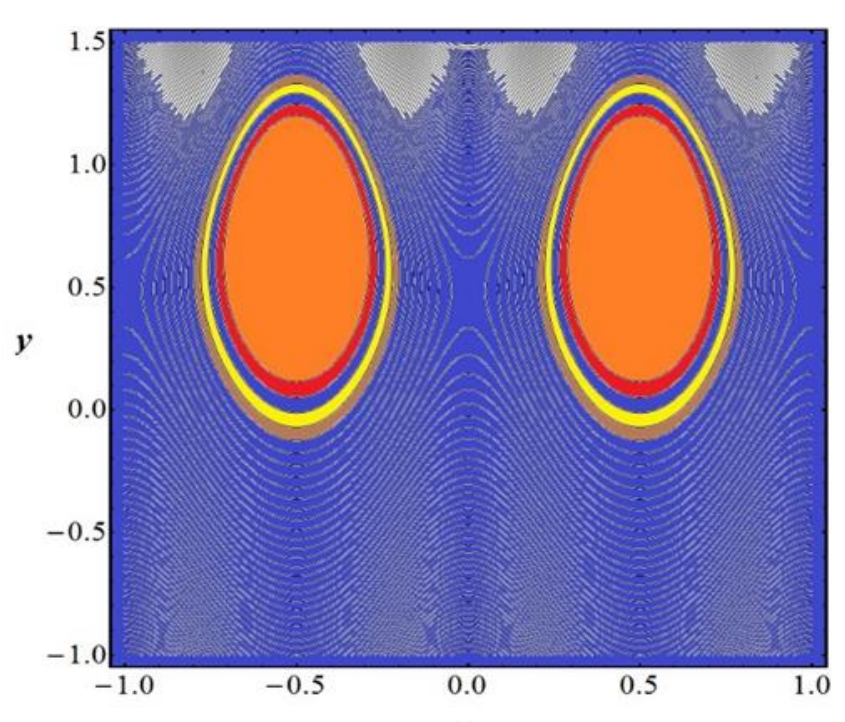

(a)

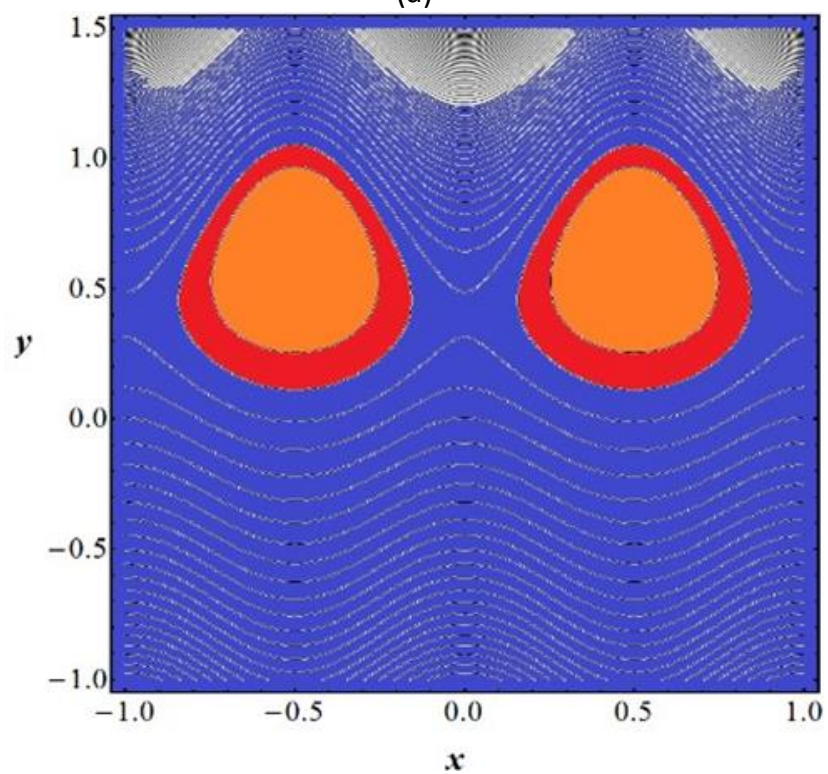

(c)

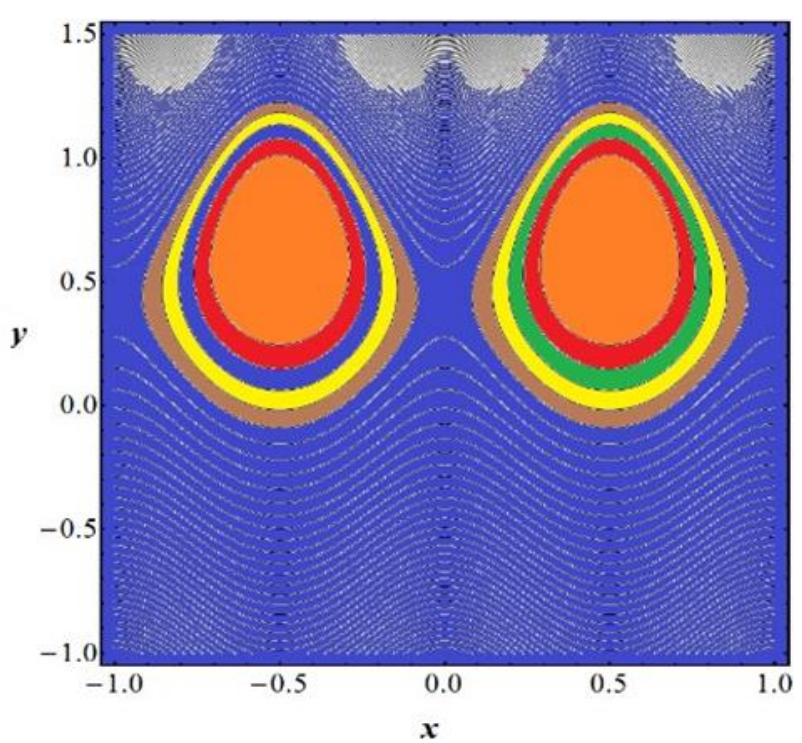

(b)

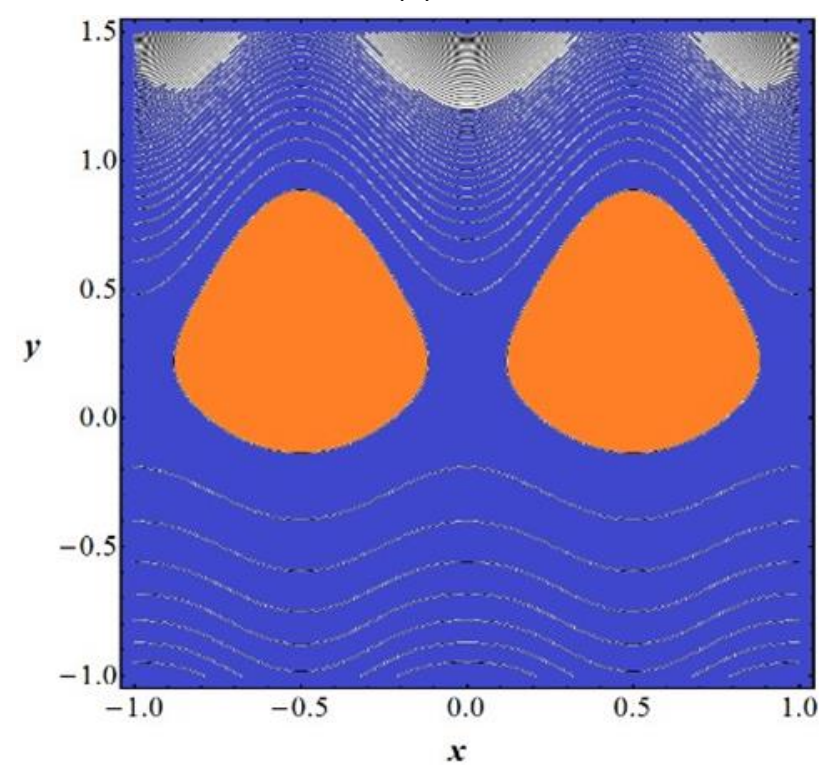

(d)

Fig. 13. Stream lines w.r.t $u_{f}$ at various values of $\mathrm{Ha}$, when $\varphi=0.6, U_{H S}=1, m=5, C=0.1$ 


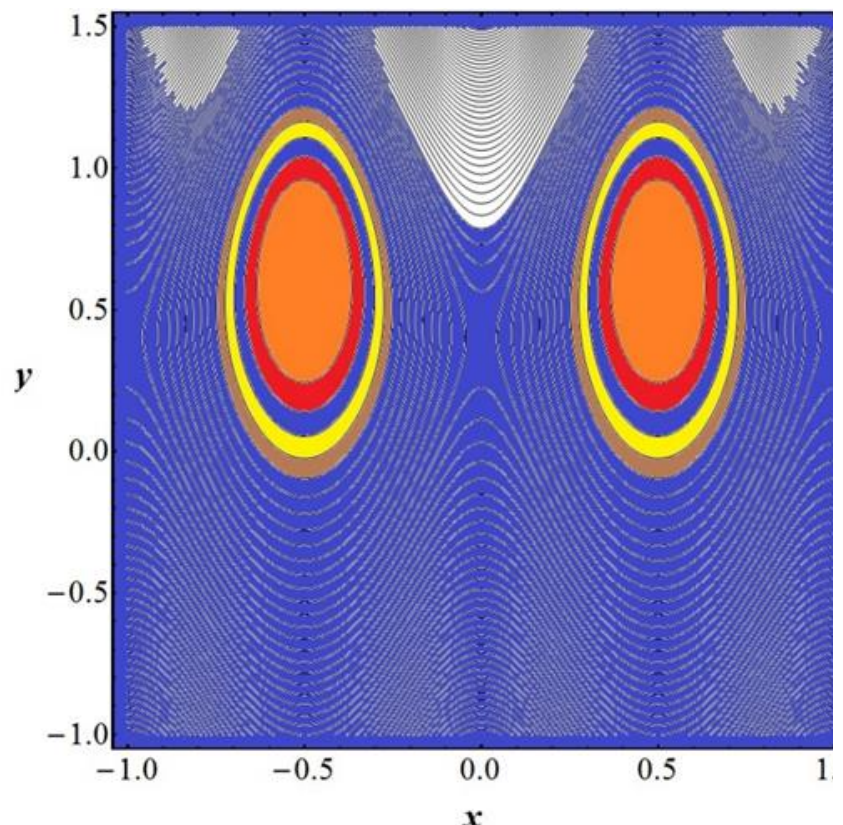

(a)

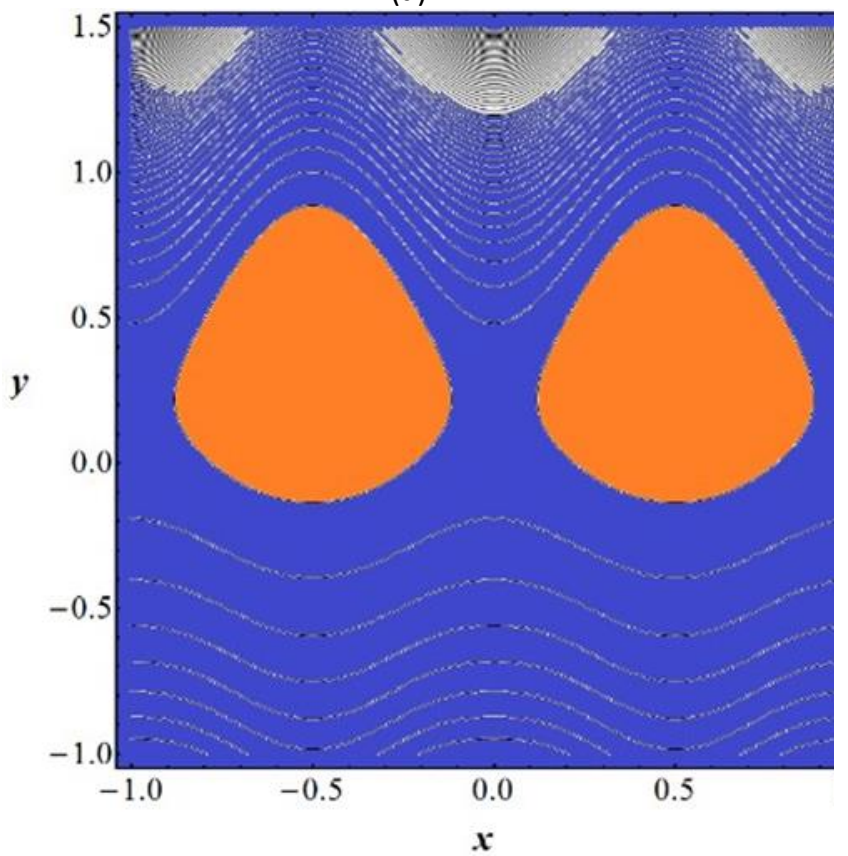

(c)

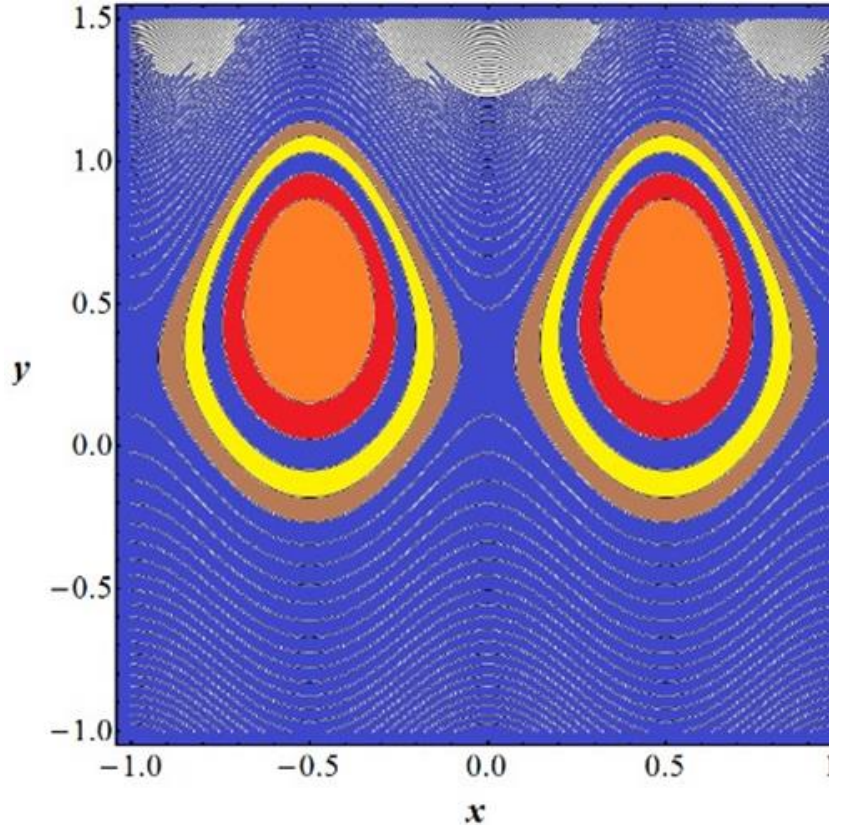

(b)

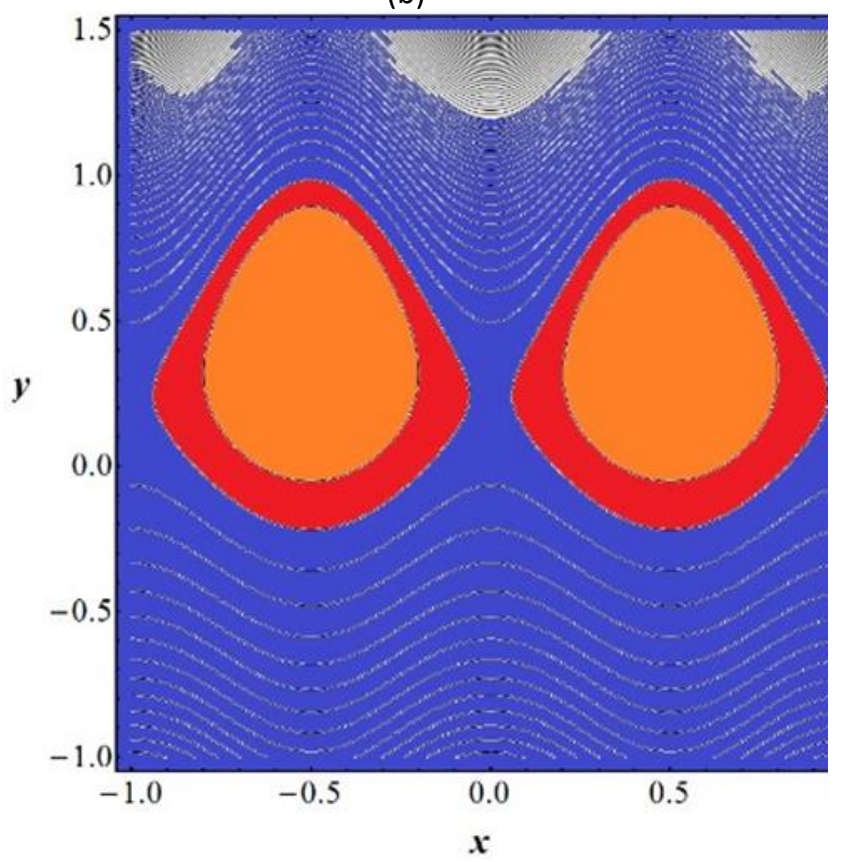

(d)

Fig. 14. Streamlines w.r.t $u_{p}$ at various values of $\mathrm{Ha}$, when $\varphi=0.6, U_{H S}=1, m=5, C=0.1$

\section{Concluding Remarks}

Effects of electro magneto-hydro-dynamics (EMHD) peristaltic flow of non-Newtonian incompressible particulate fluid containing identical rigid particles with uniform distribution in a channel of finite length $(L)$ reveals by this study. Navier stokes equations and continuity equations describes the flow. The governing equations of fluid and particulate equations are solved with the assumption of low Reynolds number, long wavelength and considering the fluid to be un-steady, electrically-conducting and incompressible. Perturbation method is employed to extract analytical solution of the resulting ordinary differential equations. The effects of the Hartman number $(\mathrm{Ha})$, Particle effect $(C)$, and Electro-osmotic parameter $(m)$ are scorched. A very significant conclusion that 
can be made on the basis of this study is that velocity is strongly affected with Joule heating parameter, electroosmotic parameter and thermophoresis parameter. A decline is observed in fluid velocity in contrast with the increase of electro-osmotic parameter $(m)$, Hartmann number and particle effect while the particulate velocity shows the opposite behaviour. The rise in pressure gradient is witnessed by rising values of Hartmann number, particle effect and electro-osmotic parameter $(\mathrm{m})$. The streamline graphs disclose the expansion in trapped bolus for fluid and particulate velocity profile by increasing Hartmann number. A rise in skin friction is noticed with the rise in particle effect and electro-osmotic parameter $(\mathrm{m})$.

\section{Acknowledgments}

This effort received funding from the National Natural Science Foundation of China, Grant/ Award Number: 11271037. We are grateful to Dr. Rabeah Saeed Kiani for grammar and punctuation check.

\section{Author Contributions}

Sudheer Khan wrote the main manuscript text and performed mathematical modeling. Shu Wang provided guidance in preparing the figures and tables and reviewed the manuscript.

\section{Competing interest}

The author(s) declare no competing interests

\section{Data Availability}

The data that supports the findings of this study are available within the article

\section{References}

[1] Nadeem, S., and Noreen Sher Akbar. "Influence of heat transfer on peristaltic transport of a Johnson-Segalman fluid in an inclined asymmetric channel." Communications in Nonlinear Science and Numerical Simulation 15, no. 10 (2010): 2860-2877. https://doi.org/10.1016/j.cnsns.2009.10.030

[2] Ali, N., M. Sajid, Z. Abbas, and O. Anwar Bég. "Swimming dynamics of a micro-organism in a couple stress fluid: a rheological model of embryological hydrodynamic propulsion." Journal of Mechanics in Medicine and Biology 17, no. 03 (2017): 1750054. https://doi.org/10.1142/S0219519417500543

[3] Afifi, N. A. S., and N. S. Gad. "Interaction of peristaltic flow with pulsatile fluid through a porous medium." Applied mathematics and computation 142, no. 1 (2003): 167-176. https://doi.org/10.1016/S0096-3003(02)00291-6

[4] Rao, A. Ramachandra, and Manoranjan Mishra. "Peristaltic transport of a power-law fluid in a porous tube." Journal of Non-Newtonian Fluid Mechanics 121, no. 2-3 (2004): 163-174. https://doi.org/10.1016/i.jnnfm.2004.06.006

[5] Bég, O. Anwar, Md Faisal Md Basir, M. J. Uddin, and Al Md Ismail. "Numerical study of slip effects on unsteady asymmetric bioconvective nanofluid flow in a porous microchannel with an expanding/contracting upper wall using Buongiorno's model." Journal of Mechanics in Medicine and Biology 17, no. 03 (2017): 1750059. https://doi.org/10.1142/S0219519417500592

[6] Latham, Thomas Walker. "Fluid motions in a peristaltic pump." PhD diss., Massachusetts Institute of Technology, 1966.

[7] Choi, S. US, and Jeffrey A. Eastman. Enhancing thermal conductivity of fluids with nanoparticles. No. ANL/MSD/CP84938; CONF-951135-29. Argonne National Lab., IL (United States), 1995.

[8] Akbar, Noreen Sher, S. Nadeem, and Changhoon Lee. "Characteristics of Jeffrey fluid model for peristaltic flow of chyme in small intestine with magnetic field." Results in Physics 3 (2013): $152-160$. https://doi.org/10.1016/i.rinp.2013.08.006

[9] Akbar, Noreen Sher, S. Nadeem, Changhoon Lee, Zafar Hayat Khan, and Rizwan UI Haq. "Numerical study of Williamson nano fluid flow in an asymmetric channel." Results in Physics 3 (2013): 161-166. https://doi.org/10.1016/i.rinp.2013.08.005

[10] Sud, V. K., G. S. Sekhon, and R. K. Mishra. "Pumping action on blood by a magnetic field." Bulletin of mathematical biology 39, no. 3 (1977): 385-390. https://doi.org/10.1016/S0092-8240(77)80075-X

[11] Srivastava, L. M., and R. P. Agarwal. "Oscillating flow of a conducting fluid with a suspension of spherical particles." (1980): 196-200. https://doi.org/10.1115/1.3153605 
[12] Agrawal HL, Anwaruddin B. "Peristaltic flow of blood in a branch." Ranchi University, 1984.

[13] Ellahi, R., M. Mubashir Bhatti, C. Fetecau, and K. Vafai. "Peristaltic flow of couple stress fluid in a non-uniform rectangular duct having compliant walls." Communications in Theoretical Physics 65, no. 1 (2016): 66. https://doi.org/10.1088/0253-6102/65/1/66

[14] Beg, O. Anwar, M. M. Rashidi, M. Akbari, and A. Hosseini. "Comparative numerical study of single-phase and twophase models for bio-nanofluid transport phenomena." Journal of Mechanics in Medicine and Biology 14, no. 01 (2014): 1450011. https://doi.org/10.1142/S0219519414500110

[15] Ramana Kumari, A. V., and G. Radhakrishnamacharya. "Effect of slip and magnetic field on peristaltic flow in an inclined channel with wall effects." International Journal of Biomathematics 5, no. 06 (2012): 1250015. https://doi.org/10.1142/S1793524511001568

[16] Aly, Emad H., and A. Ebaid. "Exact analytical solution for the peristaltic flow of nanofluids in an asymmetric channel with slip effect of the velocity, temperature and concentration." Journal of Mechanics 30, no. 4 (2014): 411-422. https://doi.org/10.1017/imech.2014.13

[17] Ebaid, Abdelhalim, and Emad H. Aly. "Exact analytical solution of the peristaltic nanofluids flow in an asymmetric channel with flexible walls and slip condition: application to the cancer treatment." Computational and mathematical methods in medicine 2013 (2013). https://doi.org/10.1155/2013/825376

[18] Reza-E-Rabbi, Sk, Sarder Firoz Ahmmed, S. M. Arifuzzaman, Tanmoy Sarkar, and Md Shakhaoath Khan. "Computational modelling of multiphase fluid flow behaviour over a stretching sheet in the presence of nanoparticles." Engineering Science and Technology, an International Journal 23, no. 3 (2020): 605-617. https://doi.org/10.1016/j.jestch.2019.07.006

[19] Reza-E-Rabbi, Sk, S. M. Arifuzzaman, Tanmoy Sarkar, Md Shakhaoath Khan, and Sarder Firoz Ahmmed. "Explicit finite difference analysis of an unsteady MHD flow of a chemically reacting Casson fluid past a stretching sheet with Brownian motion and thermophoresis effects." Journal of King Saud University-Science 32, no. 1 (2020): 690-701. https://doi.org/10.1016/j.jksus.2018.10.017

[20] Arifuzzaman, S. M., Md Shakhaoath Khan, Abdullah Al-Mamun, Sk Reza-E-Rabbi, Pronab Biswas, and Ifsana Karim. "Hydrodynamic stability and heat and mass transfer flow analysis of MHD radiative fourth-grade fluid through porous plate with chemical reaction." Journal of King Saud University-Science 31, no. 4 (2019): 1388-1398. https://doi.org/10.1016/i.jksus.2018.12.009

[21] Arifuzzaman, S. M., M. S. Khan, M. F. U. Mehedi, B. M. J. Rana, and S. F. Ahmmed. "Chemically reactive and naturally convective high speed MHD fluid flow through an oscillatory vertical porous plate with heat and radiation absorption effect." Engineering Science and Technology, an International Journal 21, no. 2 (2018): 215-228. https://doi.org/10.1016/i.jestch.2018.03.004

[22] Riaz, Arshad, S. Nadeem, and R. Ellahi. "Effects of the wall properties on unsteady peristaltic flow of an EyringPowell fluid in a three-dimensional rectangular duct." International Journal of Biomathematics 8, no. 06 (2015): 1550081. https://doi.org/10.1142/S1793524515500813

[23] Bhatti, M. M., A. Zeeshan, R. Ellahi, and N. ljaz. "Heat and mass transfer of two-phase flow with Electric double layer effects induced due to peristaltic propulsion in the presence of transverse magnetic field." Journal of Molecular Liquids 230 (2017): 237-246. https://doi.org/10.1016/j.molliq.2017.01.033

[24] Bhatti, M. M., and A. Zeeshan. "Analytic study of heat transfer with variable viscosity on solid particle motion in dusty Jeffery fluid." Modern Physics Letters B 30, no. $16 \quad$ (2016): 1650196. https://doi.org/10.1142/S0217984916501967

[25] Ijaz, N., A. Zeeshan, and M. M. Bhatti. "Peristaltic propulsion of particulate non-Newtonian Ree-Eyring fluid in a duct through constant magnetic field." Alexandria Engineering Journal 57, no. 2 (2018): 1055-1060. https://doi.org/10.1016/i.aej.2017.02.009

[26] Hariharan, Prasanna, V. Seshadri, and Rupak K. Banerjee. "Peristaltic transport of non-Newtonian fluid in a diverging tube with different wave forms." Mathematical and Computer Modelling 48, no. 7-8 (2008): 998-1017. https://doi.org/10.1016/i.mcm.2007.10.018

[27] Mekheimer, Kh S. "Effect of the induced magnetic field on peristaltic flow of a couple stress fluid." Physics Letters A 372, no. 23 (2008): 4271-4278. https://doi.org/10.1016/i.physleta.2008.03.059

[28] Gudekote, Manjunatha, and Rajashekhar Choudhari. "Slip effects on peristaltic transport of Casson fluid in an inclined elastic tube with porous walls." Journal of Advanced Research in Fluid Mechanics and Thermal Sciences 43, no. 1 (2018): 67-80.

[29] Sankar, B. Veera, and B. Rama Bhupal Reddy. "Unsteady Flow of Newtonian Fluid through Porous Medium in Two Vertical Cylinders with an Inclined Magnetic field." Journal of Computer and Mathematical Sciences 10, no. 2 (2019): 361-374. https://doi.org/10.29055/jcms/1015 
[30] Hussain, Sadaqut, Nasir Ali, and Kaleem Ullah. "Peristaltic flow of Phan-Thien-Tanner fluid: effects of peripheral layer and electro-osmotic force." Rheologica Acta 58, no. 9 (2019): 603-618. https://doi.org/10.1007/s00397-01901158-8

[31] Ravi Kiran, G., G. Radhakrishnamacharya, and O. Anwar Bég. "Peristaltic flow and hydrodynamic dispersion of a reactive micropolar fluid-simulation of chemical effects in the digestive process." Journal of Mechanics in Medicine and Biology 17, no. 01 (2017): 1750013. https://doi.org/10.1142/S0219519417500130

[32] Li, Meijing, and James G. Brasseur. "Non-steady peristaltic transport in finite-length tubes." Journal of Fluid Mechanics 248 (1993): 129-151. https://doi.org/10.1017/S0022112093000710

[33] Pal, Dulal, and Gopinath Mandal. "Influence of thermal radiation on mixed convection heat and mass transfer stagnation-point flow in nanofluids over stretching/shrinking sheet in a porous medium with chemical reaction." Nuclear Engineering and Design 273 (2014): 644-652. https://doi.org/10.1016/i.nucengdes.2014.01.032

[34] De, Poulomi, Hiranmoy Mondal, and Uttam Kumar Bera. "Influence of nanofluids on magnetohydrodynamic heat and mass transfer over a non-isothermal wedge with variable viscosity and thermal radiation." Journal of Nanofluids 3, no. 4 (2014): 391-398. https://doi.org/10.1166/jon.2014.1114

[35] Ellahi, R., A. Zeeshan, N. Shehzad, and Sultan Z. Alamri. "Structural impact of Kerosene-Al2O3 nanoliquid on MHD Poiseuille flow with variable thermal conductivity: application of cooling process." Journal of Molecular Liquids 264 (2018): 607-615. https://doi.org/10.1016/i.molliq.2018.05.103

[36] Dixit, L. A. "Unsteady flow of a dusty viscous fluid through rectangular ducts." Indian Journal of Theoretical Physics 28, no. 2 (1980): 129.

[37] Ghosh, A. K., and D. K. Mitra. "Flow of a dusty fluid through horizontal pipes." Revue Roumaine de Physique 29 , no. 7 (1984): 631-646.

[38] Mitra, P., and P. Bhattacharyya. "Unsteady hydromagnetic laminar flow of a conducting dusty fluid between two parallel plates started impulsively from rest." Acta Mechanica 39, no. 3 (1981): 171-182. https://doi.org/10.1007/BF01170340

[39] Attia, Hazem A. "Unsteady MHD Couette flow and heat transfer of dusty fluid with variable physical properties." Applied Mathematics and computation 177, no. $1 \quad$ (2006): $308-318$. https://doi.org/10.1016/i.amc.2005.11.010

[40] Golafshan, Bijan, and Asghar B. Rahimi. "Effects of radiation on mixed convection stagnation-point flow of MHD third-grade nanofluid over a vertical stretching sheet." Journal of Thermal Analysis and Calorimetry 135, no. 1 (2019): 533-549. https://doi.org/10.1007/s10973-018-7075-4

[41] Iverson, Brian D., and Suresh V. Garimella. "Recent advances in microscale pumping technologies: a review and evaluation." Microfluidics and nanofluidics 5, no. 2 (2008): 145-174. https://doi.org/10.1007/s10404-008-0266-8

[42] Peng, Zhengbiao, Jyeshtharaj B. Joshi, Behdad Moghtaderi, Md Shakhaoath Khan, Geoffrey M. Evans, and Elham Doroodchi. "Segregation and dispersion of binary solids in liquid fluidised beds: A CFD-DEM study." Chemical Engineering Science 152 (2016): 65-83. https://doi.org/10.1016/i.ces.2016.05.032

[43] Khan, Md Shakhaoath, Subhasish Mitra, Swapnil V. Ghatage, Elham Doroodchi, Jyeshtharaj B. Joshi, and Geoffrey M. Evans. "Segregation and dispersion studies in binary solid-liquid fluidised beds: A theoretical and computational study." Powder technology 314 (2017): 400-411. https://doi.org/10.1016/j.powtec.2016.12.070

[44] Buren, Mandula, and Yongjun Jian. "Electromagnetohydrodynamic (EMHD) flow between two transversely wavy microparallel plates." Electrophoresis 36, no. 14 (2015): 1539-1548. https://doi.org/10.1002/elps.201500029

[45] Su, Jie, Yongjun Jian, and Long Chang. "Thermally fully developed electroosmotic flow through a rectangular microchannel." International journal of heat and mass transfer 55, no. 21-22 (2012): 6285-6290. https://doi.org/10.1016/i.ijheatmasstransfer.2012.05.056 